OPEN ACCESS

Edited by:

Erxi Wu,

Baylor Scott and White Health,

United States

Reviewed by:

Jose Soto,

Baylor Scott and White Health,

United States

Ajay Dixit,

University of Minnesota Twin Cities,

United States

*Correspondence:

Song Chen

chensongcmu@126.com

Renyu Ding

renyuding@126.com

Specialty section:

This article was submitted to

Inflammation,

a section of the journal

Frontiers in Immunology

Received: 30 June 2021

Accepted: 08 October 2021

Published: 21 October 2021

Citation:

Miao H, Chen S and Ding R (2021)

Evaluation of the Molecular Mechanisms of Sepsis

Using Proteomics.

Front. Immunol. 12:733537. doi: 10.3389/fimmu.2021.733537

\section{Evaluation of the Molecular Mechanisms of Sepsis Using Proteomics}

\author{
$\mathrm{He} \mathrm{Miao}^{1}$, Song Chen ${ }^{2,3^{*}}$ and Renyu Ding ${ }^{1 *}$ \\ ${ }^{1}$ Department of Intensive Care Unit, The First Hospital of China Medical University, Shenyang, China, ${ }^{2}$ Department of \\ Trauma Intensive Care Unit, The First Affiliated Hospital of Hainan Medical University, Haikou, China, ${ }^{3}$ Key Laboratory of \\ Emergency and Trauma of Ministry of Education, Hainan Medical University, Haikou, China
}

Sepsis is a complex syndrome promoted by pathogenic and host factors; it is characterized by dysregulated host responses and multiple organ dysfunction, which can lead to death. However, its underlying molecular mechanisms remain unknown. Proteomics, as a biotechnology research area in the post-genomic era, paves the way for large-scale protein characterization. With the rapid development of proteomics technology, various approaches can be used to monitor proteome changes and identify differentially expressed proteins in sepsis, which may help to understand the pathophysiological process of sepsis. Although previous reports have summarized proteomics-related data on the diagnosis of sepsis and sepsis-related biomarkers, the present review aims to comprehensively summarize the available literature concerning "sepsis", "proteomics", "cecal ligation and puncture", "lipopolysaccharide", and "posttranslational modifications" in relation to proteomics research to provide novel insights into the molecular mechanisms of sepsis.

Keywords: sepsis, proteomics, cecal ligation and puncture, lipopolysaccharide, post-translational modifications

\section{INTRODUCTION}

Sepsis is a life-threatening multiple organ dysfunction resulting from a dysregulated host response to infection, including acute respiratory distress syndrome (ARDS), acute kidney injury (AKI), or disseminated intravascular coagulation (DIC) $(1,2)$. Sepsis is characterized by high morbidity and mortality. The Global Burden of Disease study identified 48.9 million cases of sepsis worldwide in 2017 (3). However, it is difficult to accurately estimate the incidence of sepsis because of the underreporting of cases in medically underdeveloped countries. Furthermore, because of an increasingly aging society in many countries, the occurrence of sepsis is likely to be on the rise (4). Although the guidelines for the diagnosis and treatment of sepsis have made great progress in the past decade and the prognosis has been improved, the mortality rate remains high. More than $25 \%-30 \%$ of patients with sepsis die of the disease, and the in-hospital mortality rate of septic shock is close to $40 \%-60 \%(4,5)$. Therefore, a deep understanding of the biological mechanism, early and accurate diagnosis, and effective treatment of sepsis is essential. 
In the last decade, various omics techniques have been used for the study of sepsis, including genomics $(6,7)$, transcriptomics (810 ), proteomics $(7)$, and metabolomics $(7,11)$. Since the completion of the Human Genome Project and accumulation of extensive genomic data, proteomics has become an integral component of the post-genomic era (12). The essence of proteomics is to study the characteristics of proteins on a large scale, including protein identification, post-translational modifications (PTMs; glycosylation, phosphorylation, etc.), and protein function determination (13). There are many research methods for proteomics, such as chromatography-based techniques (traditional techniques) (14) and protein chips (advanced technologies) $(14,15)$. However, each technology has its advantages and limitations. The following are the two most common approaches for proteomics in sepsis. The first is to search for biomarkers, which helps in the early diagnosis of sepsis and organ function damage caused by sepsis through proteomics (16). The second is to explore the molecular mechanism of sepsis and sepsis-related organ function damage by comparing the differences or dynamic changes in protein expression between sepsis and control patients to identify therapeutic targets, thereby achieving precision medicine. Herein, we reviewed proteomics studies published in the past two decades using the keywords "sepsis," "proteomics," "cecal ligation and puncture" (CLP), "lipopolysaccharide" (LPS), and "post-translational modifications." We summarize the application of proteomics in elucidating the molecular mechanism and potential therapeutic targets of sepsis and the research progress of protein PTMs in sepsis. In addition, we discuss the potential problems and development prospects of proteomics.

\section{PATHOPHYSIOLOGICAL MECHANISMS OF SEPSIS}

The detailed complex pathophysiological mechanisms underlying sepsis remain elusive; however, inflammatory and immune responses appear to play key roles in this process. Pathogens activate immune cells by interacting with pattern-recognition receptors (e.g., Toll-like receptors [TLRs]) and regulate the expression of proinflammatory factors via signaling pathways such as the TLR/MyD88/NF- $\mathrm{KB}$ and TLR/Trif/IRF3 pathways. These receptors recognize the structures of pathogenic microorganisms, known as pathogen-associated molecular patterns (PAMPs). The same receptors also recognize endogenous molecules released from injured cells, known as damage-associated molecular patterns (DAMPs), such as histones, extracellular DNA, and heat shock proteins (HSPs) (17-19). In general, proinflammatory reactions are directed at eliminating invading pathogens, whereas anti-inflammatory responses help to limit the degree of local and systemic tissue injury (20). Therefore, an imbalance between proinflammatory reactions and antiinflammatory responses results in a series of uncontrolled host responses, including systemic inflammatory response syndrome, coagulation abnormalities, immunosuppression, neuroendocrine disorders, and metabolic disorders (17, 21-23).
Coagulation abnormalities are common in sepsis (24). Proinflammatory mediators induce the expression of tissue factors and promote the cascade of coagulation pathways. Activity of the anticoagulant system (e.g., protein $\mathrm{C}$ and antithrombin) is reduced, and the increase in anti-fibrinolytic plasminogen activator inhibitor-1 levels inhibits the activation of the fibrinolytic system (20). These changes cause the formation of microthrombi, resulting in sepsis-induced coagulopathy (SIC) and even DIC (18). Neutrophil extracellular traps (NETs) (19), endothelial cell injury (25), and platelet activation (26) are all involved in the pathophysiological process of SIC.

The apoptosis of lymphocytes and antigen-presenting cells is the main pathogenic event that contributes to immunosuppression in sepsis (27). Immune checkpoints, represented by programmed death (PD)-ligand 1/PD-1, play an important role in the regulation of immune cell apoptosis $(19,28)$. Myeloid-derived suppressor cells, which are produced in high quantities during sepsis, secrete antiinflammatory cytokines, such as interleukin (IL)-10 and transforming growth factor- $\beta$, which aggravate immunosuppression (18). Impaired phagocytic function of macrophages and neutrophils and decreased expression of HLA-DR on the surface of monocytes also contribute to immunosuppression in sepsis (18).

In sepsis, the sympathetic adrenomedullary system is excited and produces large amounts of catecholamine neurotransmitters, which further increase the expression and release of proinflammatory factors, thereby aggravating endothelial cell injury (17). The cholinergic anti-inflammatory pathway associated with the vagus nerve plays a role in antagonizing the inflammatory response (20). The hypothalamus is the regulatory center of the neuroendocrine and autonomic nervous systems. The function of the hypothalamic-pituitary-adrenal axis is impaired during sepsis, resulting in relative adrenal insufficiency (29). Similarly, sepsis disturbs thyroid hormone synthesis and secretion, which causes low T3 syndrome (27).

Changes in hormone levels during sepsis can also cause metabolic disorders. The classical hormone-induced metabolic disorder is stress-induced hyperglycemia, which is associated with insulin resistance and increased glucocorticoid and glucagon levels (30). Other sepsis-related metabolic disorders include fatty acid/amino acid metabolism disorders, anaerobic metabolism, oxidative stress, and abnormalities in energy metabolism. Mitochondria are the power plants of cells that produce adenosine triphosphate (ATP) via the tricarboxylic acid (TCA) cycle and maintain cellular function (31). Mitochondrial dysfunction leads to the generation of large amounts of reactive oxygen species (ROS) and can induce cell death (e.g., mitoptosis), which plays an important role in the mechanism underlying the pathogenesis of sepsis (31). Notably, glucose metabolism pathways, including glycolysis, the TCA cycle, and oxidative phosphorylation (OXPHOS), are closely related to the function of immune cells (i.e., immune metabolism) (32). For example, in sepsis, macrophages are divided into two subtypes: M1 and M2. M1 macrophages generally exert proinflammatory effects by secreting proinflammatory factors $(33,34)$ with a cellular metabolism mode dominated by glycolysis, relatively low OXPHOS activity, and high inducible nitric oxide synthase 
(iNOS) activity (35). By contrast, M2 macrophages dominate during the resolution of inflammation by secreting antiinflammatory factors and participating in processes linked to immunosuppression and tissue repair (34). M2 macrophages rely on enhanced OXPHOS and the intact TCA cycle to support their metabolic program (36). Thus, these uncontrolled host responses are interrelated and collectively contribute to the pathophysiological process of sepsis.

Such uncontrolled host responses and the accompanying production of inflammatory mediators can damage endothelial cells present in diverse tissues and organs, causing organ dysfunction or even failure $(37,38)$ (Figure 1). The main processes contributing to organ dysfunction in sepsis are as follows $(20,22,39)$. First, endothelial cells play an essential role in maintaining organ homeostasis, including vasoregulation, selective vascular permeability, and formation of an anticoagulant surface $(40,41)$. Therefore, damage to intercellular tight junctions of endothelial cells increases their permeability; pro-inflammatory factors also induce the expression of adhesion factors on the cell and disrupt the glycocalyx to promote the adhesion and aggregation of leukocytes and platelets (40). In addition, inflammatory mediators trigger apoptotic pathways, and the apoptosis of endothelial cells exposes collagen and further induces platelet adhesion (40). The second mechanism involves shock, hypoperfusion, and microcirculatory microthrombosis, which aggravate ischemia and generate a hypoxic environment for the affected organs and tissues. Under such hypoxic conditions or in response to ischemia/reperfusion injury, damaged cells and mitochondria produce large amounts of ROS and reactive nitrogen species (RNS) (17), which can cause lipid peroxidation, destroy the cell structure, and induce cell death $(17,42)$. Moreover,
ROS/RNS can modify the post-transcriptional regulation of proteins, such as nitrosylation and acetylation, resulting in protein dysfunction, which further affects the function of cells and organs (43). In addition to these common effects, other pathophysiological mechanisms contribute to organ dysfunction in sepsis that vary depending on the cellular composition, tissue structure, and organ function (44).

As shown in Figure 1, the existing pattern of clinical presentation as a diagnostic criterion is challenged owing to the heterogeneity of sepsis (45). With the rapid development of molecular biology techniques, the analysis of biological subtypes or endogenous phenotypes of sepsis may be helpful for precise sepsis diagnosis and treatment $(46,47)$.

\section{DIFFERENT BIOLOGICAL SAMPLES IN SEPSIS PROTEOMICS}

Biological samples used in sepsis proteomics are varied and can include body fluids (such as plasma, serum, and urine), tissues or organs (such as the liver, heart, and muscle), cells (such as platelets, lymphocytes, monocytes, neutrophils, and endothelial cells), organelles (mitochondria), and exosomes. Each biological sample has its advantages and disadvantages (48). Plasma and serum are readily available samples in the clinic (49); however, plasma proteomics is the most complex form of proteomics. Plasma proteins include both proteins produced under physiological conditions and proteins secreted and shed by cells or tissues under pathological conditions. There are a wide variety of proteins in plasma, a wide range of sources, and large differences in protein content $(49,50)$. Among them, the
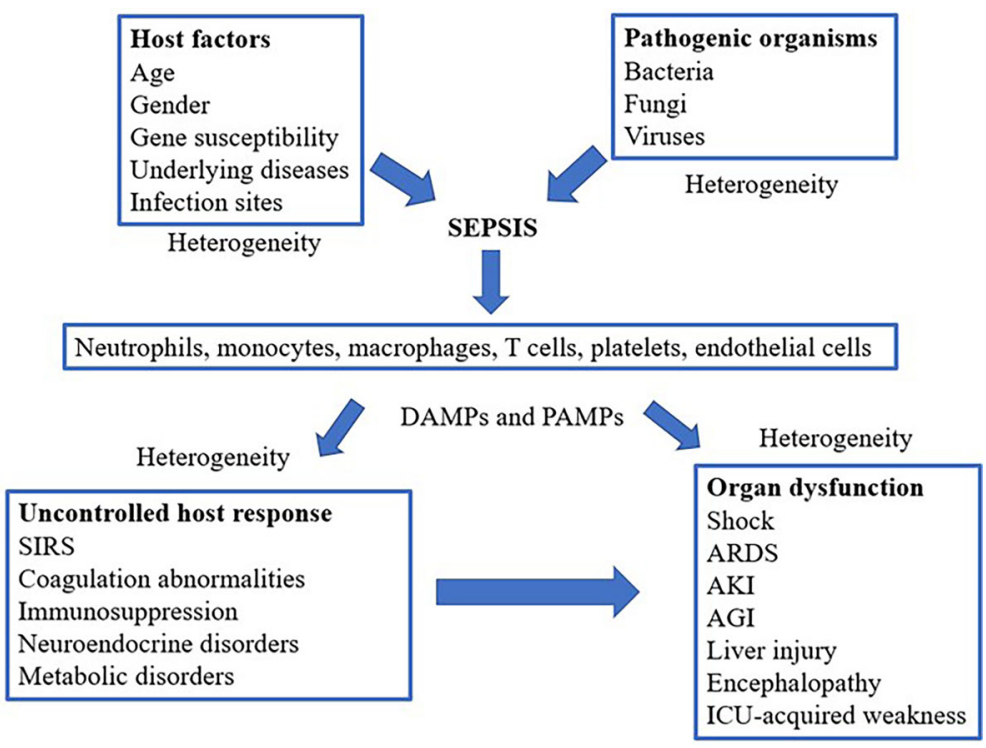

FIGURE 1 | Schematic mechanism of sepsis, including cell types involved and the pathophysiological processes leading to organ dysfunction. SIRS, systemic inflammatory response syndrome; ARDS, acute respiratory distress syndrome; AKI, acute kidney injury; AGI, acute gastrointestinal injury; DAMPS, damageassociated molecular patterns; PAMPs, pathogen-associated molecular patterns; ICU, Intensive Care Unit. 
proportion of high-abundance proteins reached approximately 99\%, including albumin, IgG, IgA, fibrinogen, transferrin, haptoglobin (HP), and antitrypsin (51, 52). Therefore, during sample preparation, thoroughly removing high-abundant proteins that interfere with the detection and enrichment of low-abundant proteins is key to identifying specific biomarkers for diseases and exploring the potential molecular mechanisms underlying diseases. Currently, there is an increasing number of technologies for the removal of high-abundance proteins from plasma. The classical methods include organic solvent solubilization or precipitation methods and affinity methods. Solvent solubilization and precipitation are consumption methods that reduce the complexity of proteomic samples by removing high-abundance proteins from proteomic samples using organic solvents, such as acetonitrile, ammonium sulfate, and ethanol. Affinity methods include those based on ligands of broad selectivity (e.g., heparin affinity and dye affinity) and those based on antibodies (e.g., immunoaffinity). Among them, the immunoaffinity approaches, which utilize immobilized antibodies for capturing one or more of the high-abundance proteins from biological samples, are the most widely used (51, 53-55). However, there is still no technology that can solve the purification problem for all proteins $(56,57)$. The current strategy is to use a combination of several different separation and purification techniques for the removal of high-abundance proteins $(49,58,59)$. The protein composition in urine is relatively stable compared to that in other body fluids. Although the amount of urinary protein is much lower than that of plasma, more than half of the protein comes from the kidney and urinary tract; therefore, urine proteomics can be used to study the pathophysiological process of kidney disease (60-62). There are proteins secreted in plasma by organs, such as the liver; however, they do not reflect the degree of organ injury (63). Direct analysis of protein expression in organs is therefore beneficial for further understanding the mechanism of organ injury in sepsis. Nonetheless, organs and tissues can only be obtained through animal experiments or autopsies (64). Cytoproteomics is a proteomics technique that uses cells as samples. The cells most closely related to the occurrence and development of sepsis include neutrophils, endothelial cells, platelets, and monocytes. In addition, these cells usually do not include high-abundance proteins (64). The exosome is a bilayer vesicle secreted by cells into the extracellular space that contains proteins, non-coding RNAs, mRNAs, and lipids. It is involved in biological processes, such as immune response, tumor cell migration and invasion, and cell signaling (65-67). Exosomes are present in most body fluids (blood, urine, saliva) and cell culture media $(68,69)$; additionally, exosomes are one of the sources for screening protein biomarkers (48). Nevertheless, the preparation of exosomes is a complex and time-consuming process (48).

\section{PROTEOMICS IN BASIC RESEARCH}

Because sepsis can easily cause cardiovascular, lung, kidney, liver, and other organ dysfunction-leading to a poor prognosis-in recent years, researchers have begun to focus on the changes in protein expression in various organs in sepsis models and devoted themselves to exploring the molecular mechanism of multiple organ injuries in sepsis. Various animal models of sepsis can currently be induced by surgical (e.g., CLP, cecal ligation and incision, colon ascendant stent peritonitis) or non-surgical means (injection of bacteria or exogenous molecules) to mimic the hemodynamic and immunological changes in human sepsis. The most common of these is the CLP procedure in rodents (48, $64,70,71)$. The results of proteomic studies performed in animal models are summarized in Table $\mathbf{1}$.

\section{Renal Proteomics}

The kidney is one of the most vulnerable organs in sepsis patients. A total of $22 \%-51 \%$ of sepsis patients admitted in intensive care units experience AKI $(87,88)$. Understanding the mechanism of AKI in sepsis is therefore essential for the treatment of sepsis patients. The pathophysiological mechanism of AKI in sepsis is unknown. Microvascular dysfunction, inflammation, and metabolic reprogramming are currently considered basic mechanisms of septic AKI (89). Septic AKI still occurs without hemodynamic instability and marked hypoperfusion, even with increased renal blood flow. Inflammatory mediators, including PAMPs and DAMPs released after pathogen invasion, bind to TLRs expressed on immune cells, endothelial cells, and tubular epithelial cells, resulting in endothelial activation, tissue injury, and oxidative stress (89). This series of events ultimately leads to microvascular thrombosis and altered flow continuity (intermittent or no flow) (89). Furthermore, during septic AKI, energy is re-prioritized in the quest to meet vital metabolic needs, prioritizing survival at the expense of cellular function $(87,89,90)$. Kellum and Prowle (91) summarized the pathogenesis of AKI caused by various factors. They stated that the main mechanism of AKI in sepsis is an excessive inflammatory response. Róka et al. (72) studied the renal proteome in sepsis and found that renal proteome change was milder in the early phases (1.5 and $6 \mathrm{~h})$ than in the late phases (24 and $48 \mathrm{~h}$ ). Changes in acute phase proteins (APPs) were the most evident. Of these, lipocalin-2, complement C3, fibrinogen, haptoglobin, and hemopexin were the most upregulated APPs. To further study the molecular mechanism of sepsis-related renal injury, Matejovic et al. (73) selected pigs injected with Pseudomonas aeruginosa for kidney biopsy and dynamic proteomics analysis. Twenty differentially expressed proteins were distinguished between the sepsis and control groups. Their study showed that endoplasmic reticulum stress (78 kDa glucose-regulated protein), oxidative stress (peroxiredoxin-6), mitochondrial energy metabolism (enoylCoA hydratase), tubular transport (chloride intracellular channel protein 4), and immune/inflammatory signaling (annexin A1, and laminin subunit gamma-1) are activation pathways of AKI in sepsis. Hinkelbein et al. (74) performed proteomic analysis in renal tissues from healthy rats and rats with CLP sepsis ( 24 and $48 \mathrm{~h}$ following CLP). The expression of cytochrome c oxidase subunit B (COX5B) was lower in the 48-h sepsis group than in the control and 24-h groups. Cytochrome oxidase (Complex IV) is an enzyme located at the end of the electron transport chain in the inner mitochondrial membrane 
TABLE 1 | Summary of proteomics studies of sepsis infection using animal models.

\begin{tabular}{|c|c|c|c|c|}
\hline Species & Sample & Sepsis Model & Altered Pathways & Proteins \\
\hline Mouse & Kidney & Injected with LPS & Acute phase response & $\begin{array}{l}\text { Upregulated: Lipocalin-2, Complement C3, Fibrinogen, Haptoglobin } \\
\text { and Hemopexin }\end{array}$ \\
\hline Pig & Kidney & $\begin{array}{l}\text { Injected with } \\
\text { pseudomonas } \\
\text { aeruginosa }\end{array}$ & $\begin{array}{l}\text { Endoplasmic reticulum (ER) stress, } \\
\text { oxidative stress, mitochondrial energy } \\
\text { metabolism, tubular transport, and } \\
\text { immune/inflammatory signaling }\end{array}$ & $\begin{array}{l}\text { Downregulated: Enoyl-CoA hydratase (cellular energetics), and } \\
\text { Chloride intracellular channel protein } 4 \text { (transporter) } \\
\text { Upregulated: } 78 \text { kDa glucose-regulated protein (ER stress), } \\
\text { Peroxiredoxin-6 (oxidative stress protein), Annexin A1(signal } \\
\text { transduction), and Laminin subunit gamma-1(cytoskeleton) }\end{array}$ \\
\hline Rat & Kidney & CLP & Mitochondrial energy production & Downregulated: COX5B (48 hours after CLP compared to 24 hours) \\
\hline Rat & Brain & CLP & $\begin{array}{l}\text { Stress, glycolysis, and mitochondrial } \\
\text { energy production }\end{array}$ & $\begin{array}{l}\text { Downregulated: Chaperone proteins, Enolase and Glucose-6- } \\
\text { phosphate dehydrogenase, Creatine kinase isoenzyme and Aconitase } \\
\text { 2, Glutamate oxaloacetate transaminase 1, HSP60 ( } 24 \text { h) } \\
\text { Glyceraldehyde-3-phosphate dehydrogenase, Aldolase A ( } 48 \text { h) } \\
\text { Upregulated: G protein beta } 1 \text { subunit and COP9 signalosome } \\
\text { complex subunit } 4 \text { (48 h) }\end{array}$ \\
\hline Rat & $\begin{array}{l}\text { Cerebral } \\
\text { cortex }\end{array}$ & CLP & $\begin{array}{l}\text { Coagulation, signaling, immune } \\
\text { response, and energy metabolism }\end{array}$ & $\begin{array}{l}\text { Downregulated: Glandular kallikrein-10, and Succinate } \\
\text { dehydrogenase, } \\
\text { Upregulated: Alpha-2 macroglobulin, Prolyl endopeptidase, Serine } \\
\text { protease inhibitor A3N, Kininogen 2, and Alpha-1-acid glycoprotein }\end{array}$ \\
\hline Mouse & Brain & CLP & Immune and coagulation & $\begin{array}{l}\text { Downregulated: SMAD4, DPYS, PTGDS } \\
\text { Upregulated: CUL4A }\end{array}$ \\
\hline Cat & $\begin{array}{l}\text { Liver } \\
\text { mitochondria }\end{array}$ & Injected with LPS & $\begin{array}{l}\text { Reactive oxygen species production } \\
\text { and lipid metabolism }\end{array}$ & $\begin{array}{l}\text { Downregulated: HSP70, F1-ATPase and key enzymes regulating lipid } \\
\text { metabolism (Acyl-CoA dehydrogenase and HMG-CoA synthase) } \\
\text { Upregulated: Urea cycle enzymes (Carbamoyl phosphate synthetase-1, } \\
\text { Ornithine transcarbamylase), HSP } 60 \text { and Manganese superoxide } \\
\text { dismutase }\end{array}$ \\
\hline Rat & $\begin{array}{l}\text { Hepatic } \\
\text { mitochondria }\end{array}$ & CLP & Mitochondrial functions & $\begin{array}{l}\text { Downregulated: MP1 and MP2 } \\
\text { Upregulated: MP3 }\end{array}$ \\
\hline Mouse & Liver & CLP & $\begin{array}{l}\text { Acute phase proteins, oxidative } \\
\text { stress, apoptosis, and nitric oxide } \\
\text { metabolism }\end{array}$ & $\begin{array}{l}\text { Downregulated: Fibrinogen } \beta \text { precursor }(6 \text { h), Carbamoyl phosphate } \\
\text { synthetase ( } 24 \text { h) } \\
\text { Upregulated: Calgranulin B, Cyclophilin A (6 h), and Amyloid formation } \\
(12 \text { h) }\end{array}$ \\
\hline Mouse & Lung & CLP & $\begin{array}{l}\text { Muscle contraction, oxygen } \\
\text { transport, protein synthesis, collagen } \\
\text { barrier membranes, cell adhesion, } \\
\text { and coagulation function }\end{array}$ & $\begin{array}{l}\text { Downregulated: Transferrin } \\
\text { Upregulated: Myosin light chain 4, Cardiomyopathy associated protein } \\
\text { 5, Myoglobin, Hemoglobin subunit, 60S ribosomal protein L6,28,34, } \\
\text { Fibrinogen alpha chain, Matrix metalloproteinase-9, Tissue-type } \\
\text { plasminogen activator, Semaphorin-7A, OTULIN and MAP3K1 }\end{array}$ \\
\hline Rat & Heart & CLP & Mitochondrial function & $\begin{array}{l}\text { Downregulated: Acyl-CoA synthetase 2-like, 2-oxoglutarate } \\
\text { dehydrogenase E1 component, Oxoglutarate dehydrogenase, 2- } \\
\text { oxoglutarate dehydrogenase complex, and Succinate Coenzyme A } \\
\text { ligase (members of the Krebs cycle) }\end{array}$ \\
\hline Rat & $\begin{array}{l}\text { Skeletal } \\
\text { muscle }\end{array}$ & CLP & $\begin{array}{l}\text { Oxidative stress and mitochondrial } \\
\text { dysfunction }\end{array}$ & $\begin{array}{l}\text { Downregulated: HSP60, HSP27, HSP } \beta 6 \text {, and ATP synthase } \beta \text {-chain } \\
\text { Upregulated: SOD-1, and Ubiquitin-conjugated proteins }\end{array}$ \\
\hline Pig & Plasma & $\begin{array}{l}\text { Peritonitis-induced } \\
\text { sepsis was initiated by } \\
\text { intraperitoneal injection } \\
\text { of autologous feces }\end{array}$ & $\begin{array}{l}\text { Oxidative stress, inflammatory, and } \\
\text { cytoskeletal assembly }\end{array}$ & $\begin{array}{l}\text { Upregulated: CD14, HP, Hemopexin, Microfilament, Actin filament } \\
\text { cross-linker protein isoforms } 3 / 4 \text { and Plectin } 1\end{array}$ \\
\hline Mouse & Plasma & CLP & $\begin{array}{l}\text { Inflammation, immunity, and } \\
\text { coagulation }\end{array}$ & $\begin{array}{l}\text { Downregulated: } \alpha-2 \text { HS glycoprotein and Zinca-glycoprotein } \\
\text { (metabolism) } \\
\text { Upregulated: Transferrin, Hemopexin, HP, Serum amyloid protein P, } \\
\text { and Kininogen }\end{array}$ \\
\hline Rat & Platelet & CLP & $\begin{array}{l}\text { Platelet activation, acute phase } \\
\text { proteins, cytoskeleton structure, and } \\
\text { energy production }\end{array}$ & $\begin{array}{l}\text { Downregulated: Protein disulfide-isomerase associated 3, Glucose-6- } \\
\text { phosphate dehydrogenase, and Myosin regulatory light polypeptide } 9 \\
\text { Upregulated: Fibrinogen gamma chain, Growth factor receptor-bound } \\
\text { protein 2, Thrombospondin 1, Alpha-1-antitrypsin precursor, Tubulin } \\
\text { alpha 6, ATP synthase beta subunit, and succinate dehydrogenase } \\
\text { complex subunit B }\end{array}$ \\
\hline
\end{tabular}

Ref.

HSP, Heat shock protein; LPS, Lipopolysaccharide; CLP, Cecal ligation and puncture; COX5B, Cytochrome c oxidase subunit B;SMAD4, Mothers against decapentaplegic protein 4;

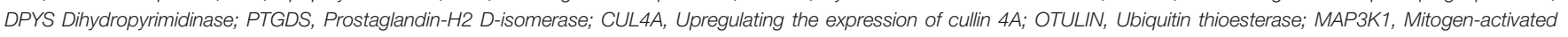
protein kinase kinase kinase 1;Hp, Haptoglobin; SOD-1, Superoxide dismutase-1.

and functions as a proton pump (92). Therefore, it is speculated that the occurrence of renal injury in sepsis is closely related to mitochondrial dysfunction. It should be mentioned that different studies yielded different results, possibly resulting from different experimental models, experimental animals, and timing (early and late phases in sepsis). 


\section{Cerebral Proteomics}

Sepsis-associated encephalopathy (SAE) is defined as diffuse brain dysfunction secondary to systemic infection (93). The manifestations are varied but lack specificity. SAE can present as delirium, agitation, and changes in consciousness (94). More than half of sepsis patients will show features of SAE (93); it can often be the first symptom of sepsis and may lead to long-term impairment $(94,95)$. Hinkelbein et al. (75) investigated the changes in brain protein expression over time in rats after sepsis induction. Twenty-four proteins were downregulatedincluding those involved in stress (chaperone proteins), glycolysis (enolase and glucose-6-phosphate dehydrogenase), and mitochondrial energy production (creatine kinase isoenzyme and aconitase 2) $-24 \mathrm{~h}$ after sepsis induction. After $48 \mathrm{~h}, 2$ proteins were upregulated ( $\mathrm{G}$ protein beta 1 subunit and COP9 signalosome complex subunit 4), and 3 metabolismrelated proteins were downregulated (glutamate oxaloacetate transaminase 1, glyceraldehyde-3-phosphate dehydrogenase, and aldolase A). Glycolysis-related enzyme production is reduced and mitochondrial function impaired, ultimately leading to impaired energy production in brain cells. In addition, chaperonin 60 (HSP60) was found to be downregulated in their study. HSP is a protein generated by cells in response to the induction of stressors (e.g., heat, infection, poisoning, trauma, etc.), and it improves the stress capacity of cells to protect them from the deleterious effects of an imbalance in proteostasis $(96,97)$. It has been shown that HSP60 also has a neuroprotective effect (98). Therefore, Hinkelbein et al. (75) suggested that the downregulation of HSP60-one of the mechanisms causing brain dysfunction in sepsis-makes brain cells more vulnerable to stress. Yang et al. (76) used isobaric tags for relative and absolute quantification (iTRAQ) technology to study the cerebral cortex of sepsis rat models and identified 91 differentially expressed proteins. These proteins are related to signaling (e.g., succinate dehydrogenase), energy metabolism (e.g., serine protease inhibitor $\mathrm{A} 3 \mathrm{~N}$ ), coagulation (e.g., kininogen 2), and immune response (e.g., alpha-1-acid glycoprotein). Among them, alpha-2 macroglobulin and kininogen, the expression of which was upregulated, act on the complement and coagulation systems, inhibit coagulation, and enhance immunity. The upregulation of prolyl endopeptidase, which hydrolyzes multiple polypeptide neurotransmitters and hormones, may lead to cognitive dysfunction in patients with SAE. The expression of glandular kallikrein-10, involved in the formation of the kallikrein-kinin system, was substantially downregulated, which may be responsible for insufficient blood supply to the brain and increased apoptosis of brain cells in patients with sepsis (76). Xie et al. (77) applied quantitative proteomics based on iTRAQ to analyze the therapeutic mechanism of $2 \%$ hydrogen inhalation on brain injury in a sepsis mouse model. A total of 39 differentially expressed proteins were identified in the study, and the functions and pathways of all proteins were analyzed using Gene Ontology (GO) functions and the Kyoto Encyclopedia of Genes and Genomes (KEGG). It was found that $\mathrm{H}_{2}$ played a role in regulating the immune system and coagulation system. Thus, the protective mechanism of $\mathrm{H}_{2}$ on $\mathrm{SAE}$ was revealed. $\mathrm{H}_{2}$ decreased SAE in septic mice by downregulating the protein expression of Drosophila mothers against decapentaplegic protein 4 (SMAD4), dihydropyrimidinase (DPYS), and prostaglandin- $\mathrm{H}_{2} \mathrm{D}$-isomerase (PTGDS), and upregulating the expression of cullin4A (CUL4A) (77).

\section{Liver Proteomics}

Wang et al. (78) demonstrated that exosomes released from LPSinduced macrophages contain several proinflammatory factors involved in the process of sepsis-induced acute liver injury by regulating the activation of multiple inflammatory pathways (e.g., the NLRP3 inflammasome pathway). It has also been reported that heat shock-induced exosomes from hepatocytes promote liver injury by activating NOD-like receptor signaling pathways (99). Liver mitochondrial proteomics analysis showed altered protein patterns associated with important metabolic pathways, such as regulating ROS production and lipid metabolism, during acute endotoxemia (100). The expression of urea cycle enzymes (carbamoyl phosphate synthetase-1 and ornithine transcarbamylase), HSP 60, and manganese superoxide dismutase increased, whereas the expression of HSP70, F1ATPase, and key enzymes regulating lipid metabolism (acylCoA dehydrogenase and HMG-CoA synthase) was decreased. Chen et al. (79) investigated the changes in liver mitochondrial proteome during sepsis and the role of heat shock treatment. The heat-shock treatment model requires to heat the whole body $24 \mathrm{~h}$ before CLP surgery after anesthetizing the rats. Rectal temperature was maintained between $41^{\circ} \mathrm{C}$ and $42^{\circ} \mathrm{C}$ for 15 min. After heat shock treatment, HSP-72 was increased in the cytoplasm of rat livers. Three variants (MP1, MP2, and MP3) of aldehyde dehydrogenase $2(\mathrm{ALDH} 2)$ were detected in rat liver mitochondria using two-dimensional gel electrophoresis (2DGE) separation and liquid chromatography with tandem mass spectrometry (LC-MS/MS) analysis. The expression of MP1 and MP2 was downregulated, whereas that of MP3 was upregulated in the early ( $9 \mathrm{~h}$ after CLP) and late (18 h after CLP) phases of sepsis. However, heat shock treatment reversed this effect. In addition, ALDH2 activity was reduced during sepsis, especially in the late phase of sepsis, as shown by an enzyme activity assay. In contrast, heat shock treatment contributed to the retention of ALDH2 activity. ALDH2 is an important oxidative stress factor in vivo. Studies have shown that its overexpression or increased activity can effectively promote the metabolism of toxic aldehydes, inhibit mitochondrial damage, and play an important role in various diseases (101-103). Dear et al. applied the 2D difference in gel electrophoresis (2D-DIGE) technique to study sepsis-induced early ( $6 \mathrm{~h}$ after CLP vs $6 \mathrm{~h}$ after sham) and late (24 h after CLP vs $6 \mathrm{~h}$ after CLP) proteomic changes in the liver and verified their abundance changes using western blotting. At $6 \mathrm{~h}$ after CLP, the protein with the greatest increase in abundance was calgranulin B and that with the greatest decrease was fibrinogen $\beta$ precursor. At $24 \mathrm{~h}$ after surgery, the protein with the greatest increase was associated with amyloid formation, and the greatest decrease was observed in carbamoyl phosphate synthetase. These and other proteins 
with altered abundance are involved in processes such as acute phase response, oxidative stress, apoptosis, and nitric oxide (NO) metabolism. One of these proteins, cyclophilin A, increased significantly at $6 \mathrm{~h}$ after CLP. Cyclophilin, one of the most abundant proteins in the cytoplasm, is involved in various cellular pathways, including immune regulation, cell signaling, transcriptional regulation, and protein folding and trafficking $(104,105)$. Notably, cyclophilin interacts with the extracellular receptor CD147 and plays an important role in the regulation of inflammatory responses in a variety of diseases (106). This group found that sepsis-induced renal injury was reduced when CD147 was inhibited, along with a significant reduction in serum cytokine production. Notably, however, the inhibition of CD147 did not significantly reduce sepsis-induced liver injury, as determined by measuring AST and ALT levels to indicate the degree of liver injury. The authors speculated that this may be owing to different pathways of liver and kidney injury in sepsis (80).

\section{Lung Proteomics}

ARDS is a clinical syndrome caused by intrapulmonary or extrapulmonary sources characterized by refractory hypoxemia. In ARDS, the common intrapulmonary and extrapulmonary causes are pneumonia and sepsis, respectively (107-109). It has been shown that $2 \%$ hydrogen can effectively ameliorate multiple organ damage and increase the survival rate of sepsis mice (110112). Bian et al. (81) identified differentially expressed proteins, and then elucidated the molecular mechanism of $\mathrm{H}_{2}$ in treating acute lung injury in sepsis using iTRAQ-based quantitative proteomics analysis. In this study, through functional enrichment analysis, the identified differentially expressed proteins were classified according to their functions, which included muscle contraction (myosin light chain 4, cardiomyopathy associated protein 5), oxygen transport (myoglobin and hemoglobin subunit), protein synthesis (60S ribosomal protein L6,28,34), collagen barrier membrane (matrix metalloproteinase-9), cell adhesion (Semaphorin-7A), and coagulation (fibrinogen alpha chain and tissue-type plasminogen activator). In addition, the expression of Semaphorin-7A, OTULIN, and MAP3K1 increased in sepsis, whereas that of transferrin decreased. $\mathrm{H}_{2}$ alleviated acute lung injury in septic mice by downregulating Semaphorin-7A, OTULIN, and MAP3K1 expression and upregulating transferrin expression. Thus, it was demonstrated that the protective effect of $\mathrm{H}_{2}$ on sepsis-related lung injury may be due to an improvement in the oxygen transport capacity of sepsis mice by alleviating mitochondrial injury and the abnormal metabolism of skeletal muscle. This leads to the strengthened contraction of the diaphragm and limb skeletal muscles, improving respiration and circulation.

\section{Heart Proteomics}

In patients with septic shock, the incidence of hypofunction is approximately $60 \%$ (113), with a high mortality rate. Some studies have applied 2D-GE, MS, and ingenuity pathway analysis to determine the changes in protein levels between sepsis and non-sepsis states (82). They found that 12 proteins were significantly altered in the heart. Among the cardiac-related differentially expressed proteins, five (acyl-CoA synthetase 2-like, 2-oxoglutarate dehydrogenase E1 component, oxoglutarate dehydrogenase, 2-oxoglutarate dehydrogenase complex, and succinate coenzyme A ligase) are members of the Krebs cycle and their expression was downregulated $48 \mathrm{~h}$ after sepsis induction. These proteins were associated with impaired energy production in the heart. Numerous studies have shown that mitochondrial reduction can cause a decrease in cardiac function in sepsis (114). Therefore, in sepsis, energy failure is an important pathophysiological mechanism leading to septic cardiomyopathy (115).

\section{Skeletal Muscle Proteomics}

In sepsis, proteins are in a hypercatabolic state (decreased synthesis and increased degradation), leading to substantial muscle atrophy. Using a model of burn-related sepsis, Duan et al. (83) identified differentially expressed proteins for muscle atrophy in sepsis. The burn-related sepsis model was established by performing CLP surgery 2 days later in animals with fullthickness skin burns reaching $20 \%$ of the total surface area. In their study, some chaperone proteins (HSP60, HSP27, and HSP $\beta 6)$ and metabolic enzymes (ATP synthase $\beta$-chain) were downregulated, while SOD-1 expression was upregulated. HSPs have a role in preventing oxidative stress, assisting protein synthesis, and repairing misfolded proteins. Thus, the downregulation of HPS exacerbates oxidative stress-induced proteolysis. The downregulation of metabolic enzyme expression may reduce cellular energy production, which may hinder protein translation (a process that requires ATP). These results suggest that oxidative stress and mitochondrial dysfunction play an essential role in sepsis-induced skeletal muscle atrophy. Duan et al. (83) also reported increased levels of ubiquitin-conjugated proteins (E2) in the muscle of rats with burn-related sepsis, suggesting that the ubiquitin-proteasome pathway is pivotal to protein metabolism in skeletal muscle. Proteins targeted for degradation via this pathway are first labeled by ubiquitin molecules mediated by ubiquitin-related enzymes (E1, E2, and E3), that is, ubiquitination of proteins, and later proteolyzed by the proteasome (116). Mass spectrometry can be used for the ubiquitination analysis of biological samples, which suggests the research prospect of proteomics in this direction.

\section{Plasma Proteomics}

Most current research techniques in plasma proteomics can remove highly abundant proteins. Nonetheless, there is no efficient method for the removal of moderately abundant proteins, and this is the key to the detection and quantification of low-abundant proteins (117). Thongboonkerd et al. (84) first used a large animal model to study the changes in the plasma proteome of sepsis. In this study, differential proteomics indicated altered plasma levels of 36 proteins (30 upregulated and 6 downregulated) representing 27 unique proteins. Among them, plasma CD14, HP (acute-phase reaction proteins and involved in oxidative stress pathways), and hemopexin (an anti-inflammatory molecule and an oxidative scavenger) were increased in early sepsis. In addition, levels of microfilament, actin filament cross-linker protein isoforms 3 and 4, and plectin 
1, which are involved in cytoskeletal assembly, were also increased. Ren et al. (85) compared differentially expressed proteins in the plasma of CLP-operated and sham-operated mice using MS and western blotting after isolating plasma proteins. Plasma protein changes were observed at $4 \mathrm{~h}$ (early phase) and $24 \mathrm{~h}$ (late phase) after CLP. They demonstrated that significant changes in plasma proteins occurred at $24 \mathrm{~h}$, but not at $4 \mathrm{~h}$ after surgery. The identified differentially expressed proteins were associated with inflammation, immunity, and coagulation. The findings suggest that the plasma abundance of fibrinogen and several plasma protease inhibitors (serine/ cysteine proteinase inhibitor) change in sepsis, emphasizing the interaction between the inflammatory response and altered coagulability. In addition, the upregulated levels of proteins involved in heme and iron metabolism (e.g., transferrin, hemopexin, HP) confirmed that iron treatment played an important role in innate immune activation. They also found downregulation of two proteins involved in metabolism, the a-2 HS glycoprotein (Fetuin A) and zinc- $\alpha$ glycoprotein.

In summary, in the proteomics of various organs during sepsis, the main pathway affected is the energy generation pathway, especially mitochondrial disorders. The downregulation of mitochondria-related proteins was found in almost all organ dysfunctions. This conclusion is consistent with that of Hohn et al. (118). In their study, differentially expressed proteins were obtained via dynamic studies $(12,24$, and $48 \mathrm{~h}$ ) of the organ proteomes and serum proteomes. Separate network analysis of these proteins revealed that changes in the sepsis organ proteome were related to redox activity, cellular energy production and metabolism, and nucleotide or nucleoside metabolism, while those in the plasma proteome were related to lipoprotein metabolism, coagulation, and inflammation.

\section{ADVANTAGES AND DISADVANTAGES OF ANIMAL MODELS}

Laboratory animals have a similar genetic inheritance and can be easily controlled for body weight and age. These factors increase the comparability of experiments but do not reflect the heterogeneity of humans (48). At the same time, this allows researchers to avoid the risks caused by experiments on humans, and researchers can obtain different samples according to the purpose of the study and even sacrifice animals. However, animal models cannot fully reproduce the complexity of human sepsis (119). Furthermore, there is no physiological monitoring in animal models, and the severity of sepsis can only be roughly estimated based on the time of death and mortality (120). The above limitations make the experimental results obtained from animal models not fully applicable in clinical practice.

\section{PROTEOMICS IN CLINICAL STUDIES}

Although sepsis can occur at all ages, sepsis in the elderly and neonates is characterized by a high incidence and high mortality
(121-123). Neonates (especially premature infants) have an immature immune system, poor immune function, and reduced immune function with age (124). Sixty percent of patients with sepsis are elderly (aged $\geq 65$ years), and this proportion may increase with an aging population (125). It has been shown that there are differences in the proteomes of sepsis patients of different ages (126). Cao et al. (126) collected plasma from community-acquired pneumonia (CAP) patients aged 5065 years and $70-85$ years, with and without sepsis, as samples for semi-quantitative plasma proteomics. Fifty-eight proteins were identified, whose expression correlated with age. These proteins were involved in acute phase response (e.g., C-reactive protein, lipopolysaccharide binding-protein, $\alpha$-1-antichymotrypsin, and transthyretin [TTR]), coagulation pathway (e.g., fibrinogen $\alpha$ chain, fibrinogen $\beta$ chain, fibrinogen $\gamma$ chain, and VWF), lipid metabolism (e.g., apolipoprotein B-100 [Apo B100], Apo C, and Apo E), atherosclerosis signaling (e.g., Apo B-100, Apo C, Apo E), and NO and ROS production (e.g., lysozyme C, and clusterin). Therefore, we next discuss the research progress of proteomics in neonatal and adult sepsis. The proteomics results in these clinical studies are summarized in Table 2.

\section{Neonatal Sepsis Proteomics}

Neonatal sepsis is divided into early and late-onset according to the time of symptom onset. Early-onset often appears within $72 \mathrm{~h}$ of birth and usually results from vertical transmission from mother to child. The late-onset form appears 3-7 days after birth and is usually caused by surrounding environmental factors (137-139). At different gestational weeks, the composition of amniotic fluid has few similarities and can be categorized into maternal serum dialysis fluid (early pregnancy), fetal urine (mid pregnancy), and pulmonary secretions (late pregnancy). The fetus swallows amniotic fluid throughout the pregnancy and is therefore directly involved in changes in amniotic fluid material (140). In addition, neutrophils in amniotic fluid are partially derived from the fetus, and assessment of the amniotic fluid reflects the fetal inflammatory response to infection $(141,142)$. Therefore, proteome analysis in amniotic fluid provides new hints for the diagnosis and prevention of neonatal sepsis. Surface-enhanced laser desorption/ionization time-of-flight MS (SELDI-TOF-MS) is a proteomics technology that combines chromatography with MS, and the analysis is based on a specific algorithm developed for retrieving information on clinically and biologically relevant biomarkers from proteomic SELDI tracing (143). First, samples to be examined are added to a protein array on the chip surface. The protein molecules bind to the chip according to their specific biological or physicochemical properties (hydrophilicity, hydrophobicity, ion exchange, and metal binding), which also facilitate their capture, retention, and purification. Unbound or non-specifically bound proteins are washed out to obtain only specific bound molecules. Finally, a chromatogram is generated using TOF-MS for identification $(144,145)$. SELDI-TOF-MS enables the use of extremely small amounts of raw biological fluids and rapid screening of numerous biological samples simultaneously (146). Buhimschi et al. (127) performed amniocentesis in 169 women with a singleton pregnancy who gave birth prematurely or with fetal 
TABLE 2 | Summary of proteomics of sepsis infection in clinical studies.

\begin{tabular}{ll}
\hline Experimental Plan & Sample \\
\hline 39 CAP patients $(50-65$ and $70-85$ years old) & Plasma
\end{tabular}

who did or did not develop severe sepsis

Patients who delivered preterm and had intraamniotic inflammation in response to infection versus patients who had symptoms of preterm labor but delivered at term Newborns with culture-confirmed EONS versus gestational age -matched controls

Survivors versus non-survivors on day 28 in Serum patients with sepsis and septic shock

Amniotic fluid

Cord blood

Serum

Adult male patients diagnosed with sepsis (non-survivors and survivors $=6$ each)

Septic patients secondary to CAP versus ageand gender-matched healthy volunteers

Peripheral blood mononuclear cells (PBMC) and polymorphonuclear cells (PMN)

Plasma

Sepsis secondary to HAP versus healthy volunteers

15 sepsis and 15 SIRS patients

Urine

Urine

Survivors versus non-survivors on day 28 in patients with sepsis

Septic patients and matched healthy controls

Platelets

Patients with septic shock

Monocytes
Lipid metabolism

Acute phase response, coagulation pathway, lipid metabolism, atherosclerosis signaling, and production of nitric oxide and reactive oxygen species

$--$

Transfer/carrier, immunity/defense, and protease/extracellular matrix

Complement replacement pathway and acute phase response

$\alpha 1$ globulins, $\alpha 2$ globulins, and danger-associated molecular patterns/Alarmins Alterations in cytoskeleton, cellular assembly, movement, lipid metabolism, and immune responses in septic patients

Inflammation, immunity, and structural or cytoskeletal processes

Biological processes of lipid homeostasis, cartilage development, iron ion transport, and certain metabolic processes

Inflammatory response and coagulation activation

Immune response and energy metabolism
Proteins

Ref

Downregulated: TTR, Apo C III, and Clusterin,

Upregulated: CRP, LBP, A1ACT, A1AG,

Fibrinogen $\alpha / \beta / \gamma$ chain, WWF, Apo B-100, Apo

$\mathrm{E}$, and Lysozyme C

MR score: Neutrophil defensins-1 and-2,

Calgranulins $\mathrm{A}$ and $\mathrm{C}$

Downregulated: Albumin, Apo A4, Apo E and Apo $\mathrm{H}$

Upregulated: HP, HpRP, AFP and VDBP

Complement factor B subunit $\mathrm{Bb}, \mathrm{HP}$, and Clusterin were more significantly upregulated in survivors $\alpha$-1-B-Glycoprotein was upregulated to a greater extent in non-survivors than in survivors

Hp, TTR, ORM1, A1AT, SAA and S100A9 exhibited differential expression patterns between survivors and non-survivors

Downregulated: Apolipoprotein family proteins; F2, GSN and PON1 (inflammation, and coagulation); PLEC, GCC2(cytoskeleton and cell motility)

Upregulated: HP, FGG, ATM, SERPINA1, SERPINA3, CRP and LBP (inflammation, and coagulation); KIF27, NF1, MYH9, MYO5B, ALMS1, SYNE1, ASPN (cytoskeleton and cell motility)

Downregulated: PON1, Apo A1, Apo C, and Apo E

Upregulated: HP, and SAA1/SAA2

Downregulated: Complement 3, SERPINA1, and Ceruloplasmin

Upregulated: Cadherin 1, and HP

Downregulated: LAMP-1 and DPP-4 (non-

survival)

Upregulated: SELENBP-1, HSPG-2, A-1-BG, HPR, and LCN (non-survival)

Upregulated: EFCAB7 (calcium ion binding), Actin (cytoskeleton), IL-1 $\beta$ (cytokine), GPIX (membrane receptor), and GPIlb (integrin) Downregulated: Oxidative phosphorylation and the Krebs cycle, $\beta$-oxidation of fatty acids, the related interferon signaling pathway, $\mathrm{MHC} \|$ antigen presentation pathway Upregulated: Glycolytic metabolism

CAP, Community-acquired pneumonia; TTR, Transthyretin; Apo, Apolipoprotein;LBP, Lipopolysaccharide binding protein; A1ACT, a-1-antichymotrypsin; A1AG a-1-acid glycoprotein; MR, Mass Restricted; CRP, C-reactive protein; EONS early-onset neonatal sepsis; HpRP, Haptoglobin-related protein; AFP, a-fetoprotein; VDBP,Vitamin-D binding-protein; GSN, a1antitrypsin, A1T1/SERPINA; serum amyloid A, SAA; orosomucoid 1/a1 acid glycoprotein, ORM1; Prothrombin, F2; Gelsolin; PON1, Paraoxonase 1; PLEC, Plectin; GCC2, GRIP and coiledcoil domain-containing protein 2; FGG, Fibrinogen gamma chain; KIF27, Kinesin-like protein KIF27; NFI, Neurofibromin; MYH9, Myosin-9; MYO5B, Unconventional myosin-Vb; ALMS1, Alstrom syndrome protein 1;SYNE1, Nesprin-1;DPP-4, Dipeptidyl peptidase-4; HPR/HP, Haptoglobin; EFCAB7, EF-hand calcium-binding domain-containing protein 7; IL, Interleukin; GPIX, Glycoprotein IX; GPIIb, Glycoprotein IIB; MHC, Major histocompatibility complex; HLA, Human leukocyte antigen.

membranes. The protein fingerprint of amniotic fluid was obtained using SELDI-TOF-MS and quantified using the mass restricted (MR) score. The MR score includes the expression of four proteins: neutrophil defensin-1 and-2 and calgranulin A and C $(64,147)$. It is used to identify amniotic inflammation and is associated with tissue chorioamnionitis and early-onset neonatal sepsis(EONS) (148). Abnormal MR scores strongly correlate with early-onset sepsis, as demonstrated by Buhimschi et al. Calgranulin A and C in amniotic fluid are associated with early-onset sepsis and neurodysplasia in neonates (148). Despite the many advantages of MR scoring, amniotic fluid is not readily available, and the functional protein network associated with early-onset sepsis cannot be directly observed (128). Proteomic analysis of cord blood was therefore performed by Buhimschi et al. (128). In their study, 19 differentially expressed proteins were identified in the cord blood of EONS cases using 2D-DIGE and MS. These proteins were classified as transfer/carrier, immunity/defense, and 
protease/extracellular matrix according to Ontological classifications. HP, haptoglobin-related protein (HpRP), afetoprotein (AFP) and vitamin-D binding-protein (VDBP) (upregulated) and albumin, Apo A4, Apo E, and Apo $\mathrm{H}$ (downregulated) are synthesized by hepatic parenchymal cells. Thus, the liver is an important organ mediating inflammatory and immune responses in EONS. In addition, Buhimschi et al. (128) confirmed using western blotting that the Hp and HpRP lanes were evident in cord blood of EONS ("switch-on") but not in neonates with non-early-onset sepsis ("switch-off"). Therefore, the HP "switch-on" pattern may become a biomarker of early sepsis in preterm infants.

\section{Adult Sepsis Proteomics}

Kalenka et al. (129) also compared the serum protein of survivors and non-survivors of sepsis or septic shock and identified six differentially expressed proteins (Complement factor B subunit $\mathrm{Bb}, \alpha-1$-B-glycoprotein, HP, and clusterin). These proteins are involved in the complement replacement pathway and acute phase response; they are part of the inflammatory and cytoprotective signaling pathways. To the best of our knowledge, this is the first serum proteomic analysis of patients with sepsis and septic shock to discover several proteins differentially expressed in survivors and non-survivors. Kalenka et al. (129) also demonstrated that proteomics is a feasible tool to identify early alterations in protein expression in patients with sepsis. In a prospective observational study, serum proteome changes from early to late stages were analyzed in sepsis survivors versus non-survivors (130). The study identified differences in the levels of HP (acute phase protein), TTR (negative acute phase protein), orosomucoid $1 / \alpha 1$ acid glycoprotein (ORM1, acute phase protein), $\alpha 1$ antitrypsin (A1AT, complement and coagulation pathways), serum amyloid A (SAA), and S100A9 (regulation of inflammatory processes and immune response) between survivors and non-survivors, especially in the early stages of sepsis. Thus, in non-survivors, a dysregulated inflammatory response may be responsible for the death. Sharma et al. (131) selected sepsis patients secondary to CAP as the study subjects to avoid patient heterogeneity and previous interventions. Proteins from sepsis patients were compared with those from age- and sex-matched healthy volunteers. Bioinformatics analysis of the differentially expressed proteins showed that proteins related to the cytoskeleton and cell motility, lipid metabolism and immune response, and other related processes were altered in patients with sepsis. Proteins related to the cytoskeleton and cell motility include those of cell assembly, such as KIF27, NF1, MYH9, MYO5B, ALMS1, SYNE1, and ASPN (upregulated); GSN, PLEC, PON1, F2, and GCC2 (downregulated); and a dynein heavy chain family member (a microtubule-dependent motor ATPase). The apolipoprotein family proteins are downregulated, such as Apo A1, Apo A2, Apo A4, Apo B, Apo C1, Apo C2, Apo C3, and Apo E. Proteins related to inflammation and coagulation include HP, FGG, ATM, SERPINA1, SERPINA3, CRP, and LBP (upregulated) and F2, GSN, and paraoxonase 1 (PON1) (downregulated). In addition, a higher expression of gelsolin and depletion of actin was observed in surviving patients. In a further assessment of lipids and lipoproteins in plasma, it was found that the total cholesterol, HDL-C, and Apo A-I levels were remarkably reduced in septic plasma (131). These results reveal that alterations in cellular structure and lipid metabolism in patients with may be the target for future interventions (131). Another study on plasma proteomics in sepsis patients secondary to hospital-acquired pneumonia (HAP) showed that impaired lipid metabolism was an important alteration in sepsis patients (132). Decreased expression of PON1 and apolipoproteins (Apo A1, Apo C, and Apo E) associated with HDL and increased expression of $\mathrm{HP}$ and SAA1/SAA2 were observed. The validation trial indicated that the total plasma cholesterol, HDL-C, LDL-C, non-HDL cholesterol, apolipoproteins ApoA1 and ApoB100, and PON1 levels were downregulated in patients with HAP. These results are similar to the changes in septic patients secondary to CAP and are consistent with the literature emphasizing the important role of lipid metabolism in the pathogenesis of sepsis (132).

Su et al. (133) identified 34 differentially expressed proteins using iTRAQ labeling and 2D-LC-MS analysis of urine from patients with sepsis and systemic inflammatory response syndrome. GO and KEGG analyses indicated that these differentially expressed proteins were involved in inflammatory, immune, and cytoskeletal processes. Among them, five specific proteins were selected by a protein-protein interaction network, which are cadherin 1 (involved in actin cytoskeletal alterations), HP (an anti-inflammatory agent), complement 3, SERPINA1 (inflammatory), and ceruloplasmin (antioxidant and anti-inflammatory defense). The same group also published another article (134), in which proteomic and bioinformatic analyses of urine from sepsis patients with different prognoses (non-survival and survival) revealed that 5 proteins were upregulated (SELENBP-1, HSPG-2, A-1-BG, HPR, and LCN) and 2 proteins were downregulated (LAMP-1 and DPP-4) in the non-survival sepsis group. Three differentially expressed proteins (LAMP-1, SBP-1, and HSPG-2) that had not been reported were validated using western immunoblotting. In non-survivors, LAMP-1 expression was significantly reduced, whereas SBP-1 and HSPG-2 expression did not differ between the survivor and non-survivor groups; thus, urinary LAMP-1 level may be considered to evaluate sepsis prognosis (134). The inflammatory response and activation of coagulation are two important responses of the host defense system in sepsis (149). The coagulation response generated by inflammation induction, in turn, promotes inflammation, and the two interact to form a positive feedback network that promotes the exacerbation of sepsis (149, 150). Neutrophils, monocytes, macrophages, platelets, and other cells play an important role in the development of sepsis. Platelets are enucleated cells, and proteomics can therefore be applied to identify changes in platelet proteins in sepsis. Liu et al. (135) applied 2-DE and MALDI-TOF-MS to identify platelet-derived differentially expressed proteins between sepsis patients and matched healthy controls. This study showed that sepsis patients have increased expression of five platelet proteins: EFCAB7 (calcium ion binding), actin (cytoskeleton), IL-1 $\beta$ (cytokine), GPIX (membrane receptor), and GPIIb (integrin) (135). These five 
proteins are involved in inflammatory response and coagulation activation, emphasizing the important role of platelets in sepsisinduced inflammation and coagulation. In contrast, in rats, $\mathrm{Hu}$ et al. measured the changes in platelet protein expression 12-24 $\mathrm{h}$ after the onset of sepsis to document the response of the platelet proteome to sepsis (86). In this study, the expression of eight proteins increased and the expression of four proteins decreased in platelets from the sepsis group compared with those from the control group. These 12 proteins were divided into the following four categories based on the biological system: 1) platelet activation (fibrinogen gamma chain, growth factor receptor-bound protein 2, and thrombospondin 1);2) acute phase proteins (protein disulfide-isomerase associated 3, alpha1-antitrypsin precursor, and thioredoxin); 3) cytoskeletal structure (myosin regulatory light polypeptide 9 and tubulin alpha 6); and 4) energy production (ATP synthase beta subunit, glucose-6-phosphate dehydrogenase, and succinate dehydrogenase complex subunit B). Zhang et al. (151) applied iTRAQ quantitative proteomics to study changes in the proteome of monocyte membranes before and after LPS treatment. A total of 1651 proteins were identified, and subcellular analysis of these proteins indicated that more than $90 \%$ of mitochondrial membrane proteins were significantly downregulated. This result demonstrates that the mitochondria may be the main target of bacterial infection in sepsis. Zhang observed that the antigen presentation molecules MHC I and MHC II responded differently to LPS treatment. MHC II molecules (CD74 and HLA-DR) were downregulated, whereas MHC I molecules (HLA-A, -B, and -C) were upregulated. De Azambuja Rodrigues et al. (136) applied LC-MS/MS to identify monocyte proteins from patients with septic shock. The downregulated proteins in sepsis have been implicated in oxidative phosphorylation and the Krebs cycle (ATP5C1, DLST, ETFB, NDUFA11 NDUFA2, NDUFS7, NDUFS8, PDK3, PDP1, PDPR, RXRA, SUCLG2, TACO1, and UQCRQ), $\beta$-oxidation of fatty acids (ACADM, DECR1, PCCA, and PCCB), the related interferon signaling pathway (EIF2AK2, EIF4A3, EIF4E2, HLA-DPA1, HLA-DQA2, HLA-DRA, HLA-DRB1, IFIT1, MX1, NUP35, OAS3, PSMB8, and UBE2L6), and MHC II antigen presentation pathway (CD74, CTSH, DCTN3, DYNC1LI2, HLA-DMA, HLA-DMB, HLA- DPA1, HLADQA2, HLA-DRA, HLA-DRB1, KIF2A, and OSBPL1A). The upregulated proteins were related to glycolytic metabolism (canonical enzymes PGK1, ALDOA, ALDOC, GADPH, PKLR GPI, and LDHA). The above proteomic results suggest that patients with septic shock show disturbances in monocyte immune response and energy metabolism. The studies by Zhang and De Azambuja Rodrigues suggest impaired monocyte antigen presentation in sepsis.

\section{DISADVANTAGES OF HUMAN SAMPLES}

Human samples are remarkably heterogeneous. The clinical symptoms and rate of progression of sepsis can vary widely among people; thus, sample collection may occur at various stages of disease progression. Secondly, proteomics studies of human tissues must be performed on post-mortem or biopsy samples. Therefore, many studies prefer to use animal experiments as the first step (64).

\section{IMPORTANT PTMS OF PROTEINS}

PTM refers to the chemical modification of proteins after translation, regulating the activity, localization, folding, and interaction between proteins and other biological macromolecules (including nucleic acids, proteins, and lipids) (152). Several studies have found that many important life activities and disease occurrence are not only correlated with the abundance of proteins but, more importantly, regulated by PTMs of various types of proteins. Through an in-depth study of the differences in the changes in PTMs, it is important to reveal the pathogenesis of diseases, screen clinical markers of diseases, and identify the targets of drugs. These typically include phosphorylation, glycosylation, ubiquitination, nitrosylation, methylation, acetylation, lipidation, and proteolysis. There are increasing studies on various protein modification omics to elucidate these PTMs. These PTM omics are often combined with proteomics to facilitate more in-depth studies of pathophysiological mechanisms or the development of new biomarkers. For example, the combined application of proteomics and phosphoproteomics can more truly reflect the relationship between protein kinases and substrates. Phosphorylation modification can be different in these proteins whose expression is not different (153). The studies of PTMs in sepsis are summarized in Table 3.

In a study conducted by Chen et al. (79), liver mitochondrial proteins in CLP rats were isolated and evaluated using twodimensional gel electrophoresis, and the protein spots were visualized using silver staining and analyzed with Bio-2D software. Three spots of the same molecular weight (MP1, MP2, and MP3) were significantly altered (79). All three spots are the same enzyme, ALDH2. During sepsis, MP1 and MP2 are downregulated, whereas MP3 is upregulated concomitantly (MP1 and MP2 shift to MP3), leading to a decrease in the ALDH2 activity. In addition, MP1 and MP2 presented a higher degree of protein phosphorylation than MP3. Thus, it is speculated that protein phosphorylation may affect ALDH2 enzymatic activity; that is, MP1 and MP2 with higher phosphorylation have a higher enzymatic activity than MP3 with lower phosphorylation (79). This study demonstrated that a PTM, phosphorylation of $\mathrm{ALDH} 2$, may play a role in the pathogenesis of sepsis and provide a new target for the therapy (79).

Wang et al. (163) found that mouse macrophage-like RAW 264.7 cells stimulated with LPS began to release a nuclear protein, high mobility group box 1 (HMGB1), after the peak release of early inflammatory factors, such as TNF and IL-1. HMGB1 plays a role in inflammatory regulation and stress response; it is an important inflammatory mediator in the late phase of sepsis and a late predictor of mortality in sepsis patients $(164,165)$. HMGB1 is a non-histone DNA-binding protein, and its function is closely related to its cellular location. Under stimulation conditions such as hypoxia and oxidative stresses, protein post-translationally modified HMGB1 translocates from 
TABLE 3 | Summary of post-translational modifications in sepsis.

\begin{tabular}{|c|c|c|c|}
\hline Protein & Type of PTM & Main Conclusions & Ref. \\
\hline ALDH2 & Phosphorylation & $\begin{array}{l}\text { MP1 and MP2 with higher phosphorylation have a higher enzymatic activity than MP3 with lower phosphorylation } \\
\text { (MP1, MP2 and MP3 are the subtypes of ALDH2). }\end{array}$ & (79) \\
\hline HMGB1 & $\begin{array}{l}\text { Redox } \\
\text { modification } \\
\text { Acetylation/ } \\
\text { deacetylation }\end{array}$ & $\begin{array}{l}\text { ROS partially oxidize HMGB1 to form disulfate-type HMGB1, inducing inflammatory cells to produce a range of } \\
\text { cytokines to promote the inflammatory response. } \\
\text { Lys acetylation after stimulation with LPS and TNF- } \alpha \text {, leads to conformational changes in HMGB1, separation from } \\
\text { SIRT1 and transport to the cytoplasm, followed by the release into the extracellular space, which would subsequently } \\
\text { activate downstream inflammatory signaling. }\end{array}$ & $\begin{array}{l}(43,154, \\
155)\end{array}$ \\
\hline Histone H3 & Citrullination & $\begin{array}{l}\text { CitH3 was significantly increased in the CLP-induced mice sepsis model. Inhibitors of PAD4 modulate citrullination } \\
\text { and reduce CitH3 levels, thereby improving survival in sepsis mice. }\end{array}$ & $(156,157)$ \\
\hline NLRP3 & $\begin{array}{l}\text { Phosphorylation } \\
\text { Ubiquitylation }\end{array}$ & $\begin{array}{l}\text { Phosphorylation of serine } 5 \text { in the PYD inhibits the activation of NLRP3. } \\
\text { Sequential ubiquitination of NLRP3 by RNF125 and Cbl-b inhibits the activation of NLRP3 and prevents the } \\
\text { development of sepsis in mice. }\end{array}$ & $(158,159)$ \\
\hline $\begin{array}{l}\text { Cysteine } \\
\text { residues of } \\
\text { various signaling } \\
\text { proteins }\end{array}$ & Nitrosylation & $\begin{array}{l}\text { SIRT1 activity decreases with increasing S-nitrosylation of SIRT1, resulting in extracellular HMGB1 release. } \\
\text { Increased levels of iNOS, leading to enhanced production of NO, induces S-nitrosylation of SIRT1. } \\
\text { During the transformation of LPS-stimulated macrophages from the resting state to the M1 type, the expression levels } \\
\text { of iNOS and NO were increased, and mitochondrial complexes I and IV were modified by nitrosylation, resulting in the } \\
\text { destruction of the mitochondrial electron transfer chain and inhibition of OXPHOS. }\end{array}$ & $(160-162)$ \\
\hline
\end{tabular}

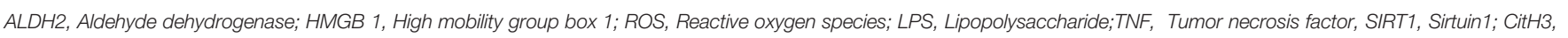

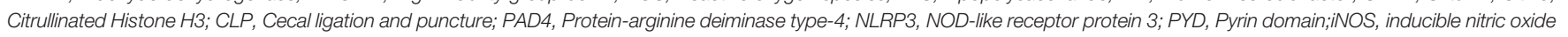
synthase; NO, Nitric oxide; OXPHOS, Oxidative phosphorylation.

the nucleus to the cytoplasm or is released into the extracellular space. Acetylation, glycosylation, phosphorylation, ADPribosylation, methylation, and redox are the main PTMs of HMGB 1. Cys 23, Cys 45, and Cys 106 are key sites for their redox modification, and acetylation and phosphorylation mainly act on HMGB 1 nuclear localization sequences (NLSs) (164). Under physiological conditions, nuclear HMGBl is a perthioltype HMGBl in the reduced state. The Cys23, Cys45, and Cysl06 sites connect the thiol side chains (166). ROS generation increases in the perivascular endothelium and tubules of the kidney in an LPS-induced sepsis model. ROS partially oxidize HMGBl to form disulfate-type HMGBl, which confers its cytokine activity and induces inflammatory cells to produce a range of cytokines to promote the inflammatory response (43). In murine macrophage RAW264.7 cells, SIRTl interacts with multiple Lys28-30 on HMGBl to form a complex (154). Lys acetylation after stimulation with LPS and TNF- $\alpha$ leads to conformational changes in HMGBl, separation from SIRTl, and transport to the cytoplasm, followed by the release into the extracellular space, which would subsequently activate downstream inflammatory signaling. In a mouse model of endotoxemia, deacetylation-mediated interaction of SIRT1HMGB1 improves survival (155).

Histones are highly conserved basic cationic proteins in the cellular chromatin of eukaryotic organisms and are mainly divided into core histones (H2A, H2B, H3, and H4) and linker histones (H1 and H5). The important function of histones is PTMs, including acetylation, methylation, phosphorylation, ubiquitinylation, citrullination, acylation, or glycosylation of ADP. When histones are released into the extracellular space, they are called extracellular histones. The production pathways of extracellular histones include passive necrosis (the membrane is damaged by mechanical trauma or charge- or detergent-related toxicity), NETosis/ETosis (neutrophils/macrophages), necroptosis, pyroptosis, and ferroptosis (167-169). Xu et al. (170) demonstrated that extracellular histones have cytotoxic effects in vivo and in vitro.
In addition, extracellular histones are an endogenous DAMP. By acting on the TLR, they activate various downstream pathways, release many proinflammatory factors (e.g., IL-6, IL-10, TNF- $\alpha$ ), and induce platelet aggregation $(171,172)$. It has been shown that in sepsis patients, circulating histone levels are increased and can cause multiple organ damage (173). This may be caused by a combination of the above mechanisms. There is a close link between the citrullination of histone $\mathrm{H} 3$ and sepsis (174). Circulating citrullinated histone $\mathrm{H} 3$ (CitH3, a component of NETs) was significantly increased in the CLP-induced mouse sepsis model (156). Inhibitors of protein-arginine deiminase type-4 (PAD4, an enzyme that promotes $\mathrm{CitH} 3$ production) modulate this citrullination and reduce $\mathrm{CitH} 3$ levels, thereby improving survival in sepsis mice (157). Thus, extracellular histones are involved in the development of sepsis; however, the pathogenic mechanism of their PTMs in sepsis needs further study.

Inflammasomes are protein complexes that promote the maturation and secretion of the cytokines pro-IL-1 $\beta$ and pro-IL18 by activating caspase-1 (175). There are five inflammasomes, of which the NLRP3 inflammasome plays a key role in sepsis and multiple organ dysfunction as an important component of innate immunity (176). Lee et al. (177) found that NLRP3 deficiency suppressed inflammatory response and improved survival in sepsis mice. Zhong et al. (178) showed that the inhibition of the NLRP3/ caspase-1/IL-1 $\beta$ pathway in macrophages attenuated the inflammatory response and microvascular leakage resulting from sepsis. NLRP3 is regulated by a variety of PTMs, including phosphorylation, ubiquitination, alkylation, S-nitrosylation, and ADP-ribosylation $(179,180)$. Using quantitative proteomics, Stutz et al. (158) found three phosphorylation sites for NLRP3. Among them, they found that the phosphorylation of serine 5 in the pyrin domain inhibits the activation of NLRP3 inflammasome. Phosphatase 2A (PP2A) inhibitors were confirmed using MS to cause increased phosphorylation of serine 5 in LPS-induced macrophages, thereby inhibiting NLRP3 activation. Tang et al. (159) found that RNF125 and Cbl-b (two E3 ubiquitin ligases) 
sequentially ubiquitinate NLRP3 to inhibit its activation and prevent the development of sepsis in mice. Thus, PTMs of NLRP3, particularly phosphorylation and ubiquitination, regulate its activation and play an important role in sepsis (181).

In sepsis, inflammatory mediators and cytokines induce iNOS production in various cells. NO generated by iNOS combines with the superoxide anion $\mathrm{O}_{2}{ }^{-}$to generate peroxynitrite. $\mathrm{NO}$ and peroxynitrite can affect the PTM, especially nitrosylation, of cysteine residues in various signaling proteins, such as those involved in excitation-contraction coupling, contraction, energy supply, anti-apoptosis, and anti-oxidative stress (182). SNitrosylation refers to the oxidative modification of cysteine by NO to form protein S-nitrosothiols (183). As mentioned above, acetylation of the lysine residues of HMGB1 leads to the release of HMGB1 into the extracellular space (155). SIRT1 activity decreases with increasing S-nitrosylation of SIRT1, resulting in extracellular HMGB1 release (160). Increased levels of iNOS, leading to enhanced production of NO, induce S-nitrosylation of SIRT1 (161). S-Nitroso-N-acetylpenicillamine, as a donor of NO, can increase both S-nitrosylated-SIRT1 levels and the consequent release of HMGB1 (160). NO and NO-mediated PTM can also regulate macrophage immunometabolism (184). Bailey et al. (185) showed that NO modulates the levels of essential TCA cycle-associated metabolites (e.g., citrate and succinate), the inflammatory mediator itaconate, and the complex I subunit in the respiratory chain in inflammatory murine macrophages. NO can also regulate mitochondrial fatty acid metabolism through reversible protein S-nitrosylation (186). During the transformation of LPS-stimulated macrophages from the resting state to the M1 type, the expression of iNOS and NO was increased, and mitochondrial complexes I and IV were modified by nitrosylation, resulting in the destruction of the mitochondrial electron transfer chain and inhibition of OXPHOS (162). Knockdown of iNOS ameliorated LPS-induced mitochondrial respiratory function impairment in M1 macrophages and promoted enhanced OXPHOS. However, treatment of exogenous NO caused mitochondrial dysfunction and promoted macrophage proinflammatory responses (187).

In summary, protein PTMs can affect the development of sepsis by regulating various signaling pathways. At present, proteins with PTMs in sepsis samples can be identified, and the modified amino acid sites can be located using MS combined with bioinformatics analysis.

\section{CONCLUSIONS}

Proteomics is a product of the post-genomic era and can be used to study the characteristics of proteins on a large scale. It is mainly used in medicine in the following aspects: 1 ) to identify markers for the diagnosis or prognosis of a disease, 2) to elucidate the mechanism of the disease and find potential therapeutic targets, and 3) for the classification of diseases. In this review, we have shown that proteomics has made a great contribution to the elucidation of the molecular mechanisms of sepsis; however, it still has some limitations. First, being a molecular technique, there are some inherent challenges. For example, the identification of low-abundance proteins is difficult. The development of protein isolation and identification techniques has provided many effective methods for identifying low-abundance proteins, but they are still not very satisfactory $(188,189)$. In addition, proteomics cannot be used to detect and identify unknown proteins. Second, biomarkers discovered using proteomics are rarely applied in the clinic, which may be because the number of samples studied is small, and there is high individual heterogeneity. The widespread clinical application of biomarkers requires population-scale validation of their effectiveness. The high cost and time-consuming nature of proteomics is also one of the reasons why most candidate markers are not applied in the clinic. Proteomics is usually employed as the first step in screening biomarkers, but it cannot determine the absolute concentration of proteins present in a sample. Large-scale screening of differentially expressed proteins is performed using high-throughput proteomics, and the sample size then needs to be expanded for the validation of potential biomarkers. Subsequently, western blotting or an enzyme-linked immunoassay is required to determine the expression of candidate biomarkers. Finally, the biomarkers are translated into targets with clinical application value (58). However, there is still a lack of standard techniques and methods for the evaluation and confirmation of the obtained biomarkers to determine their clinical value (58). At present, proteomics research on PTMs mainly focuses on tumors and cardiovascular diseases, and there are few studies on sepsis. In addition, post-translationally modified proteins are low in content in samples and have a wide dynamic range; therefore, enrichment is required to improve the abundance of modified proteins before mass spectrometry $(190,191)$. In summary, proteomics as a clinical application technology requires much improvement.

Despite the many limitations of proteomics, it is still used to revolutionize our insights into the complex biological processes of sepsis. Moreover, using proteomics in combination with genomics and metabolomics may help comprehensively understand the pathophysiological mechanisms underlying sepsis, determine potential biomarkers, and improve our approach to precision medicine (192).

\section{AUTHOR CONTRIBUTIONS}

HM designed the review and drafted the manuscript. RD and SC reviewed and revised the article. All authors contributed to the article and approved the submitted version.

\section{FUNDING}

This study was supported by the grant from LiaoNing Revitalization Talents Program (Grant No. XLYC2007001) and the grant from Changjiang Scholars Program of Ministry of Education of China (TG2019081) and the Natural Science Foundation of Hainan Province (Grant No. 819QN222) and the National Natural Science Foundation of China (Grant No. 81960346, No. 82172174). 


\section{REFERENCES}

1. Coopersmith CM, De Backer D, Deutschman CS, Ferrer R, Lat I, Machado FR, et al. Surviving Sepsis Campaign: Research Priorities for Sepsis and Septic Shock. Intensive Care Med (2018) 44(9):1400-26. doi: 10.1007/ s00134-018-5175-z

2. Singer M, Deutschman CS, Seymour CW, Shankar-Hari M, Annane D, Bauer $\mathrm{M}$, et al. The Third International Consensus Definitions for Sepsis and Septic Shock (Sepsis-3). JAMA (2016) 315(8):801-10. doi: 10.1001/jama.2016.0287

3. Rudd KE, Johnson SC, Agesa KM, Shackelford KA, Tsoi D, Kievlan DR, et al. Global, Regional, and National Sepsis Incidence and Mortality, 19902017: Analysis for the Global Burden of Disease Study. Lancet (2020) 395 (10219):200-11. doi: 10.1016/s0140-6736(19)32989-7

4. Cecconi M, Evans L, Levy M, Rhodes A. Sepsis and Septic Shock. Lancet (London England) (2018) 392(10141):75-87. doi: 10.1016/S0140-6736(18) 30696-2

5. Jawad I, Luksic I, Rafnsson SB. Assessing Available Information on the Burden of Sepsis: Global Estimates of Incidence, Prevalence and Mortality. J Glob Health (2012) 2(1):010404. doi: 10.7189/jogh.02.010404

6. Maslove DM, Wong HR. Gene Expression Profiling in Sepsis: Timing, Tissue, and Translational Considerations. Trends Mol Med (2014) 20 (4):204-13. doi: 10.1016/j.molmed.2014.01.006

7. Skibsted S, Bhasin MK, Aird WC, Shapiro NI. Bench-To-Bedside Review: Future Novel Diagnostics for Sepsis - a Systems Biology Approach. Crit Care (London England) (2013) 17(5):231. doi: 10.1186/cc12693

8. Mommert M, Tabone O, Guichard A, Oriol G, Cerrato E, Denizot M, et al. Dynamic LTR Retrotransposon Transcriptome Landscape in Septic Shock Patients. Crit Care (London England) (2020) 24(1):96. doi: 10.1186/s13054020-2788-8

9. Burnham KL, Davenport EE, Radhakrishnan J, Humburg P, Gordon AC, Hutton P, et al. Shared and Distinct Aspects of the Sepsis Transcriptomic Response to Fecal Peritonitis and Pneumonia. Am J Respir Crit Care Med (2017) 196(3):328-39. doi: 10.1164/rccm.201608-1685OC

10. Tang BM, Huang SJ, McLean AS. Genome-Wide Transcription Profiling of Human Sepsis: A Systematic Review. Crit Care (London England) (2010) 14 (6):R237. doi: 10.1186/cc9392

11. Lee J, Banerjee D. Metabolomics and the Microbiome as Biomarkers in Sepsis. Crit Care Clinics (2020) 36(1):105-13. doi: 10.1016/j.ccc.2019.08.008

12. Mocellin S, Rossi CR, Traldi P, Nitti D, Lise M. Molecular Oncology in the Post-Genomic Era: The Challenge of Proteomics. Trends Mol Med (2004) 10 (1):24-32. doi: 10.1016/j.molmed.2003.11.001

13. Petricoin EF, Zoon KC, Kohn EC, Barrett JC, Liotta LA. Clinical Proteomics: Translating Benchside Promise Into Bedside Reality. Nat Rev Drug Discov (2002) 1(9):683-95. doi: 10.1038/nrd891

14. Aslam B, Basit M, Nisar MA, Khurshid M, Rasool MH. Proteomics: Technologies and Their Applications. J Chromatogr Sci (2017) 55(2):18296. doi: 10.1093/chromsci/bmw167

15. Yu X, Schneiderhan-Marra N, Joos TO. Protein Microarrays for Personalized Medicine. Clin Chem (2010) 56(3):376-87. doi: 10.1373/ clinchem.2009.137158

16. Ludwig KR, Hummon AB. Mass Spectrometry for the Discovery of Biomarkers of Sepsis. Mol Biosyst (2017) 13(4):648-64. doi: 10.1039/ c6mb00656f

17. Arina P, Singer M. Pathophysiology of Sepsis. Curr Opin Anaesthesiol (2021) 34(2):77-84. doi: 10.1097/aco.0000000000000963

18. Jarczak D, Kluge S, Nierhaus A. Sepsis-Pathophysiology and Therapeutic Concepts. Front Med (Lausanne) (2021) 8:628302. doi: 10.3389/ fmed.2021.628302

19. Cheng Z, Abrams ST, Toh J, Wang SS, Wang Z, Yu Q, et al. The Critical Roles and Mechanisms of Immune Cell Death in Sepsis. Front Immunol (2020) 11:1918. doi: 10.3389/fimmu.2020.01918

20. Angus DC, van der Poll T. Severe Sepsis and Septic Shock. N Engl J Med (2013) 369(9):840-51. doi: 10.1056/NEJMra1208623

21. Gotts JE, Matthay MA. Sepsis: Pathophysiology and Clinical Management. Bmj (2016) 353:i1585. doi: 10.1136/bmj.i1585

22. Ling-ling S, Yan-qiu H, Hui-juan R, Yang L, Jing Z. Research Advance of Pathology and Physiology of Sepsis. Chin J Nosocomiol (2016) 26(08):1914-6. doi: 10.11816/cn.ni.2016-152123
23. Denning NL, Aziz M, Gurien SD, Wang P. DAMPs and NETs in Sepsis. Front Immunol (2019) 10:2536. doi: 10.3389/fimmu.2019.02536

24. Wu R, Wang N, Comish PB, Tang D, Kang R. Inflammasome-Dependent Coagulation Activation in Sepsis. Front Immunol (2021) 12:641750. doi: $10.3389 /$ fimmu.2021.641750

25. Okamoto T, Suzuki K. The Role of Gap Junction-Mediated Endothelial CellCell Interaction in the Crosstalk Between Inflammation and Blood Coagulation. Int J Mol Sci (2017) 18(11):2254. doi: 10.3390/ijms18112254

26. Levi M, van der Poll T. Inflammation and Coagulation. Crit Care Med (2010) 38(2 Suppl):S26-34. doi: 10.1097/CCM.0b013e3181c98d21

27. Ding R, Meng Y, Ma X. The Central Role of the Inflammatory Response in Understanding the Heterogeneity of Sepsis-3. BioMed Res Int (2018) 2018:5086516. doi: 10.1155/2018/5086516

28. McBride MA, Patil TK, Bohannon JK, Hernandez A, Sherwood ER, Patil NK. Immune Checkpoints: Novel Therapeutic Targets to Attenuate SepsisInduced Immunosuppression. Front Immunol (2020) 11:624272. doi: 10.3389/fimmu.2020.624272

29. Schurr JW, Szumita PM, DeGrado JR. Neuroendocrine Derangements in Early Septic Shock: Pharmacotherapy for Relative Adrenal and Vasopressin Insufficiency. Shock (2017) 48(3):284-93. doi: 10.1097/shk.0000000000000864

30. Appiah MG, Park EJ, Akama Y, Nakamori Y, Kawamoto E, Gaowa A, et al. Cellular and Exosomal Regulations of Sepsis-Induced Metabolic Alterations. Int J Mol Sci (2021) 22(15):8295. doi: 10.3390/ijms22158295

31. Preau S, Vodovar D, Jung B, Lancel S, Zafrani L, Flatres A, et al. Energetic Dysfunction in Sepsis: A Narrative Review. Ann Intensive Care (2021) 11 (1):104. doi: 10.1186/s13613-021-00893-7

32. Wang X, Buechler NL, Woodruff AG, Long DL, Zabalawi M, Yoza BK, et al. Sirtuins and Immuno-Metabolism of Sepsis. Int J Mol Sci (2018) 19(9):2738 doi: $10.3390 / \mathrm{ijms} 19092738$

33. Liu YC, Zou XB, Chai YF, Yao YM. Macrophage Polarization in Inflammatory Diseases. Int J Biol Sci (2014) 10(5):520-9. doi: 10.7150/ ijbs. 8879

34. Shen Y, Song J, Wang Y, Chen Z, Zhang L, Yu J, et al. M2 Macrophages Promote Pulmonary Endothelial Cells Regeneration in Sepsis-Induced Acute Lung Injury. Ann Transl Med (2019) 7(7):142. doi: 10.21037/atm.2019.02.47

35. Kumar V. Targeting Macrophage Immunometabolism: Dawn in the Darkness of Sepsis. Int Immunopharmacol (2018) 58:173-85. doi: 10.1016/ j.intimp.2018.03.005

36. Viola A, Munari F, Sánchez-Rodríguez R, Scolaro T, Castegna A. The Metabolic Signature of Macrophage Responses. Front Immunol (2019) 10:1462. doi: 10.3389/fimmu.2019.01462

37. Huang M, Cai S, Su J. The Pathogenesis of Sepsis and Potential Therapeutic Targets. Int J Mol Sci (2019) 20(21):5376. doi: 10.3390/ijms20215376

38. van der Poll T, van de Veerdonk FL, Scicluna BP, Netea MG. The Immunopathology of Sepsis and Potential Therapeutic Targets. Nat Rev Immunol (2017) 17(7):407-20. doi: 10.1038/nri.2017.36

39. Lelubre C, Vincent JL. Mechanisms and Treatment of Organ Failure in Sepsis. Nat Rev Nephrol (2018) 14(7):417-27. doi: 10.1038/s41581-018-0005-7

40. Joffre J, Hellman J, Ince C, Ait-Oufella H. Endothelial Responses in Sepsis. Am J Respir Crit Care Med (2020) 202(3):361-70. doi: 10.1164/rccm.2019101911TR

41. Dauphinee SM, Karsan A. Lipopolysaccharide Signaling in Endothelial Cells. Lab Invest (2006) 86(1):9-22. doi: 10.1038/labinvest.3700366

42. Berg RM, Møller K, Bailey DM. Neuro-Oxidative-Nitrosative Stress in Sepsis. J Cereb Blood Flow Metab (2011) 31(7):1532-44. doi: 10.1038/ jcbfm. 2011.48

43. Abdulmahdi W, Patel D, Rabadi MM, Azar T, Jules E, Lipphardt M, et al. HMGB1 Redox During Sepsis. Redox Biol (2017) 13:600-7. doi: 10.1016/ j.redox.2017.08.001

44. Yan L, Qian L. Clinical Research Progress on the Mechanism of Multiple Organ Damage Caused by Sepsis. J Jinzhou Med Univ (2020) 41(04):108-12. doi: $10.13847 /$ j.cnki.lnmu.2020.04.026

45. Seymour CW, Kennedy JN, Wang S, Chang CH, Elliott CF, Xu Z, et al. Derivation, Validation, and Potential Treatment Implications of Novel Clinical Phenotypes for Sepsis. Jama (2019) 321(20):2003-17. doi: 10.1001/jama.2019.5791

46. Stanski NL, Wong HR. Prognostic and Predictive Enrichment in Sepsis. Nat Rev Nephrol (2020) 16(1):20-31. doi: 10.1038/s41581-019-0199-3 
47. Leligdowicz A, Matthay MA. Heterogeneity in Sepsis: New Biological Evidence With Clinical Applications. Crit Care (2019) 23(1):80. doi: 10.1186/s13054-019-2372-2

48. Blangy-Letheule A, Persello A, Rozec B, Waard M, Lauzier B. New Approaches to Identify Sepsis Biomarkers: The Importance of Model and Sample Source for Mass Spectrometry. Oxid Med Cell Longev (2020) 2020:6681073. doi: 10.1155/2020/6681073

49. Lin L, Zheng J, Yu Q, Chen W, Xing J, Chen C, et al. High Throughput and Accurate Serum Proteome Profiling by Integrated Sample Preparation Technology and Single-Run Data Independent Mass Spectrometry Analysis. J Proteomics (2018) 174:9-16. doi: 10.1016/j.jprot.2017.12.014

50. Anderson NL, Anderson NG. The Human Plasma Proteome: History, Character, and Diagnostic Prospects. Mol Cell Proteomics MCP (2002) 1 (11):845-67. doi: 10.1074/mcp.R200007-MCP200

51. Lee PY, Osman J, Low TY, Jamal R. Plasma/serum Proteomics: Depletion Strategies for Reducing High-Abundance Proteins for Biomarker Discovery. Bioanalysis (2019) 11(19):1799-812. doi: 10.4155/bio-2019-0145

52. Issaq HJ, Xiao Z, Veenstra TD. Serum and Plasma Proteomics. Chem Rev (2007) 107(8):3601-20. doi: 10.1021/cr068287r

53. Selvaraju S, Rassi ZE. Liquid-Phase-Based Separation Systems for Depletion, Prefractionation and Enrichment of Proteins in Biological Fluids and Matrices for in-Depth Proteomics Analysis-an Update Covering the Period 2008-2011. Electrophoresis (2012) 33(1):74-88. doi: 10.1002/ elps.201100431

54. Puangpila C, Mayadunne E, El Rassi Z. Liquid Phase Based Separation Systems for Depletion, Prefractionation, and Enrichment of Proteins in Biological Fluids and Matrices for in-Depth Proteomics Analysis-An Update Covering the Period 2011-2014. Electrophoresis (2015) 36(1):238-52. doi: 10.1002/elps.201400434

55. El Rassi Z, Puangpila C. Liquid-Phase Based Separation Systems for Depletion, Prefractionation, and Enrichment of Proteins in Biological Fluids and Matrices for in-Depth Proteomics Analysis-An Update Covering the Period 2014-2016. Electrophoresis (2017) 38(1):150-61. doi: 10.1002/elps.201600413

56. Linke T, Doraiswamy S, Harrison EH. Rat Plasma Proteomics: Effects of Abundant Protein Depletion on Proteomic Analysis. J chromatogr B Anal Technol Biomed Life Sci (2007) 849(1-2):273-81. doi: 10.1016/ j.jchromb.2006.11.051

57. Tu C, Rudnick PA, Martinez MY, Cheek KL, Stein SE, Slebos RJC, et al. Depletion of Abundant Plasma Proteins and Limitations of Plasma Proteomics. J Proteome Res (2010) 9(10):4982-91. doi: 10.1021/pr100646w

58. Geyer PE, Holdt LM, Teupser D, Mann M. Revisiting Biomarker Discovery by Plasma Proteomics. Mol Syst Biol (2017) 13(9):942. doi: 10.15252/ msb. 20156297

59. Lee H-J, Lee E-Y, Kwon M-S, Paik Y-K. Biomarker Discovery From the Plasma Proteome Using Multidimensional Fractionation Proteomics. Curr Opin Chem Biol (2006) 10(1):42-9. doi: 10.1016/j.cbpa.2006.01.007

60. Fliser D, Novak J, Thongboonkerd V, Argilés A, Jankowski V, Girolami MA, et al. Advances in Urinary Proteome Analysis and Biomarker Discovery. J Am Soc Nephrol JASN (2007) 18(4):1057-71. doi: 10.1681/ ASN.2006090956

61. Jiang S, Wang Y, Liu Z. The Application of Urinary Proteomics for the Detection of Biomarkers of Kidney Diseases. Adv Exp Med Biol (2015) 845:151-65. doi: 10.1007/978-94-017-9523-4_15

62. Caubet C, Lacroix C, Decramer S, Drube J, Ehrich JHH, Mischak H, et al. Advances in Urinary Proteome Analysis and Biomarker Discovery in Pediatric Renal Disease. Pediatr Nephrol (Berlin Germany) (2010) 25 (1):27-35. doi: 10.1007/s00467-009-1251-5

63. Malmström E, Kilsgård O, Hauri S, Smeds E, Herwald H, Malmström L, et al. Large-Scale Inference of Protein Tissue Origin in Gram-Positive Sepsis Plasma Using Quantitative Targeted Proteomics. Nat Commun (2016) 7:10261. doi: 10.1038/ncomms10261

64. Cao Z, Robinson RAS. The Role of Proteomics in Understanding Biological Mechanisms of Sepsis. Proteomics Clin Appl (2014) 8(1-2):35-52. doi: 10.1002/prca.201300101

65. Lässer C, Eldh M and Lötvall J. Isolation and Characterization of RNAContaining Exosomes. J Visualized Exp JoVE (2012) 59):e3037. doi: 10.3791/ 3037
66. Simpson RJ, Jensen SS and Lim JWE. Proteomic Profiling of Exosomes: Current Perspectives. Proteomics (2008) 8(19):4083-99. doi: 10.1002/ pmic.200800109

67. Xu Y, Ku X, Wu C, Cai C, Tang J and Yan W. Exosomal Proteome Analysis of Human Plasma to Monitor Sepsis Progression. Biochem Biophys Res Commun (2018) 499(4):856-61. doi: 10.1016/j.bbrc.2018.04.006

68. Lässer C, Alikhani VS, Ekström K, Eldh M, Paredes PT, Bossios A, et al. Human Saliva, Plasma and Breast Milk Exosomes Contain RNA: Uptake by Macrophages. J Trans Med (2011) 9:9. doi: 10.1186/1479-5876-9-9

69. Simpson RJ, Lim JW, Moritz RL, Mathivanan S. Exosomes: Proteomic Insights and Diagnostic Potential. Expert Rev Proteomics (2009) 6(3):26783. doi: $10.1586 /$ epr.09.17

70. Buras JA, Holzmann B, Sitkovsky M. Animal Models of Sepsis: Setting the Stage. Nat Rev Drug Discovery (2005) 4(10):854-65. doi: 10.1038/nrd1854

71. Rittirsch D, Huber-Lang MS, Flierl MA, Ward PA. Immunodesign of Experimental Sepsis by Cecal Ligation and Puncture. Nat Protoc (2009) 4 (1):31-6. doi: 10.1038/nprot.2008.214

72. Róka B, Tod P, Kaucsár T, Vizovišek M, Vidmar R, Turk B, et al. The Acute Phase Response Is a Prominent Renal Proteome Change in Sepsis in Mice. Int J Mol Sci (2019) 21(1):200. doi: 10.3390/ijms21010200

73. Matejovic M, Tuma Z, Moravec J, Valesova L, Sykora R, Chvojka J, et al. Renal Proteomic Responses to Severe Sepsis and Surgical Trauma: Dynamic Analysis of Porcine Tissue Biopsies. Shock (2016) 46(4):453-64. doi: 10.1097/SHK.0000000000000613

74. Hinkelbein J, Bohm L, Braunecker S, Adler C, De Robertis E, Cirillo F. Decreased Tissue COX5B Expression and Mitochondrial Dysfunction During Sepsis-Induced Kidney Injury in Rats. Oxid Med Cell Longev (2017) 2017:8498510. doi: 10.1155/2017/8498510

75. Hinkelbein J, Feldmann RE, Peterka A, Schubert C, Schelshorn D, Maurer $\mathrm{MH}$, et al. Alterations in Cerebral Metabolomics and Proteomic Expression During Sepsis. Curr Neurovascular Res (2007) 4(4):280-8. doi: 10.2174/ 156720207782446388

76. Yang Q, Chen Q, Yang G, Cao Y, Lu W. Proteomic Study of Septic Encephalopathy Based on iTRAQ Technology. Chin J Clin Pharmacol Ther (2019) 24(11):1269-74. doi: 10.12092/j.issn.1009-2501.2019.11.009

77. Xie K, Lian N, Kan Y, Yang M, Pan J, Yu Y, et al. iTRAQ-Based Quantitative Proteomic Analysis of the Therapeutic Effects of 2\% Hydrogen Gas Inhalation on Brain Injury in Septic Mice. Brain Res (2020) 1746:147003. doi: 10.1016/j.brainres.2020.147003

78. Wang G, Jin S, Ling X, Li Y, Hu Y, Zhang Y, et al. Proteomic Profiling of LPS-Induced Macrophage-Derived Exosomes Indicates Their Involvement in Acute Liver Injury. Proteomics (2018) 19(3):e1800274. doi: 10.1002/ pmic. 201800274

79. Chen HW, Kuo HT, Hwang LC, Kuo MF, Yang RC. Proteomic Alteration of Mitochondrial Aldehyde Dehydrogenase 2 in Sepsis Regulated by Heat Shock Response. Shock (2007) 28(6):710-6. doi: 10.1097/ shk.0b013e318050c8c2

80. Dear JW, Leelahavanichkul A, Aponte A, Hu X, Constant SL, Hewitt SM, et al. Liver Proteomics for Therapeutic Drug Discovery: Inhibition of the Cyclophilin Receptor CD147 Attenuates Sepsis-Induced Acute Renal Failure. Crit Care Med (2007) 35(10):2319-28. doi: 10.1097/ 01.CCM.0000281858.44387.A2

81. Bian Y, Qin C, Xin Y, Yu Y, Chen H, Wang G, et al. Itraq-Based Quantitative Proteomic Analysis of Lungs in Murine Polymicrobial Sepsis With Hydrogen Gas Treatment. Shock (2018) 49(2):187-95. doi: 10.1097/ SHK.0000000000000927

82. Hinkelbein J, Kalenka A, Schubert C, Peterka A, Feldmann RE. Proteome and Metabolome Alterations in Heart and Liver Indicate Compromised Energy Production During Sepsis. Protein Pept Lett (2010) 17(1):18-31. doi: 10.2174/092986610789909520

83. Duan X, Berthiaume F, Yarmush D, Yarmush ML. Proteomic Analysis of Altered Protein Expression in Skeletal Muscle of Rats in a Hypermetabolic State Induced by Burn Sepsis. Biochem J (2006) 397(1):149-58. doi: 10.1042/ BJ20051710

84. Thongboonkerd V, Chiangjong W, Mares J, Moravec J, Tuma Z, Karvunidis T, et al. Altered Plasma Proteome During an Early Phase of PeritonitisInduced Sepsis. Clin Sci (Lond) (2009) 116(9):721-30. doi: 10.1042/ CS20080478 
85. Ren Y, Wang J, Xia J, Jiang C, Zhao K, Li R, et al. The Alterations of Mouse Plasma Proteins During Septic Development. J Proteome Res (2007) 6 (7):2812-21. doi: 10.1021/pr070047k

86. Hu JY, Li CL, Wang YW. Altered Proteomic Pattern in Platelets of Rats With Sepsis. Blood Cells Mol Dis (2012) 48(1):30-5. doi: 10.1016/j.bcmd.2011.09.010

87. Bellomo R, Kellum JA, Ronco C, Wald R, Martensson J, Maiden M, et al. Acute Kidney Injury in Sepsis. Intensive Care Med (2017) 43(6):816-28. doi: 10.1007/s00134-017-4755-7

88. Vincent JL, Sakr Y, Sprung CL, Ranieri VM, Reinhart K, Gerlach H, et al. Sepsis in European Intensive Care Units: Results of the SOAP Study. Crit Care Med (2006) 34(2):344-53. doi: 10.1097/01.ccm.0000194725.48928.3a

89. Peerapornratana S, Manrique-Caballero CL, Gómez H, Kellum JA. Acute Kidney Injury From Sepsis: Current Concepts, Epidemiology, Pathophysiology, Prevention and Treatment. Kidney Int (2019) 96 (5):1083-99. doi: 10.1016/j.kint.2019.05.026

90. Poston JT, Koyner JL. Sepsis Associated Acute Kidney Injury. Bmj (2019) 364:k4891. doi: 10.1136/bmj.k4891

91. Kellum JA, Prowle JR. Paradigms of Acute Kidney Injury in the Intensive Care Setting. Nat Rev Nephrol (2018) 14(4):217-30. doi: 10.1038/ nrneph.2017.184

92. Kadenbach B, Hüttemann M, Arnold S, Lee I, Bender E. Mitochondrial Energy Metabolism is Regulated via Nuclear-Coded Subunits of Cytochrome C Oxidase. Free Radical Biol Med (2000) 29(3-4):211-21. doi: 10.1016/S0891-5849(00)00305-1

93. Gofton TE, Young GB. Sepsis-Associated Encephalopathy. Nat Rev Neurol (2012) 8(10):557-66. doi: 10.1038/nrneurol.2012.183

94. Chung H-Y, Wickel J, Brunkhorst FM, Geis C. Sepsis-Associated Encephalopathy: From Delirium to Dementia? J Clin Med (2020) 9 (3):703. doi: $10.3390 / \mathrm{jcm} 9030703$

95. Helbing D-L, Böhm L, Witte OW. Sepsis-Associated Encephalopathy. CMAJ Can Med Assoc J = J l'Assoc Med Can (2018) 190(36):E1083. doi: 10.1503/ cmaj. 180454

96. Lindquist S, Craig EA. The Heat-Shock Proteins. Annu Rev Genet (1988) 22:631-77. doi: 10.1146/annurev.ge.22.120188.003215

97. Morimoto RI, Santoro MG. Stress-Inducible Responses and Heat Shock Proteins: New Pharmacologic Targets for Cytoprotection. Nat Biotechnol (1998) 16(9):833-8. doi: 10.1038/nbt0998-833

98. Chan JYH, Cheng HL, Chou JLJ, Li FCH, Dai KY, Chan SHH, et al. Heat Shock Protein 60 or 70 Activates Nitric-Oxide Synthase (NOS) I- and Inhibits NOS II-Associated Signaling and Depresses the Mitochondrial Apoptotic Cascade During Brain Stem Death. J Biol Chem (2007) 282 (7):4585-600. doi: 10.1074/jbc.M603394200

99. Li Y, Zhu X, Zhang M, Tong H, Su L. Heatstroke-Induced Hepatocyte Exosomes Promote Liver Injury by Activating the NOD-Like Receptor Signaling Pathway in Mice. PeerJ (2019) 7:e8216. doi: 10.7717/peerj.8216

100. Crouser ED, Julian MW, Huff JE, Mandich DV, Green-Church KB. A Proteomic Analysis of Liver Mitochondria During Acute Endotoxemia. Intensive Care Med (2006) 32(8):1252-62. doi: 10.1007/s00134-006-0224-4

101. Zhao Y, Wang B, Zhang J, He D, Zhang Q, Pan C, et al. ALDH2 (Aldehyde Dehydrogenase 2) Protects Against Hypoxia-Induced Pulmonary Hypertension. Arteriosclerosis Thrombosis Vasc Biol (2019) 39(11):230319. doi: 10.1161/ATVBAHA.119.312946

102. Kang P, Wang J, Fang D, Fang T, Yu Y, Zhang W, et al. Activation of ALDH2 Attenuates High Glucose Induced Rat Cardiomyocyte Fibrosis and Necroptosis. Free Radical Biol Med (2020) 146:198-210. doi: 10.1016/ j.freeradbiomed.2019.10.416

103. Long P, He M, Yan W, Chen W, Wei D, Wang S, et al. ALDH2 Protects Naturally Aged Mouse Retina Inhibiting Oxidative Stress-Related Apoptosis and Enhancing Unfolded Protein Response in Endoplasmic Reticulum. Aging (2020) 13(2):2750-67. doi: 10.18632/aging.202325

104. Dawar FU, Xiong Y, Khattak MNK, Li J, Lin L and Mei J. Potential Role of Cyclophilin A in Regulating Cytokine Secretion. J Leukoc Biol (2017) 102 (4):989-92. doi: 10.1189/jlb.3RU0317-090RR

105. Nigro P, Pompilio G, Capogrossi MC. Cyclophilin A: A Key Player for Human Disease. Cell Death Dis (2013) 4:e888. doi: 10.1038/cddis.2013.410

106. Yurchenko V, Constant S, Eisenmesser E, Bukrinsky M. Cyclophilin-CD147 Interactions: A New Target for Anti-Inflammatory Therapeutics. Clin Exp Immunol (2010) 160(3):305-17. doi: 10.1111/j.1365-2249.2010.04115.x
107. Pelosi P, D’Onofrio D, Chiumello D, Paolo S, Chiara G, Capelozzi VL, et al. Pulmonary and Extrapulmonary Acute Respiratory Distress Syndrome are Different. Eur Respir J Suppl (2003) 42:48s-56s. doi: 10.1183/ 09031936.03.00420803

108. Thompson BT, Chambers RC, Liu KD. Acute Respiratory Distress Syndrome. New Engl J Med (2017) 377(6):562-72. doi: 10.1056/NEJMra1608077

109. Gajic O, Dabbagh O, Park PK, Adesanya A, Chang SY, Hou P, et al. Early Identification of Patients at Risk of Acute Lung Injury: Evaluation of Lung Injury Prediction Score in a Multicenter Cohort Study. Am J Respir Crit Care Med (2011) 183(4):462-70. doi: 10.1164/rccm.201004-0549OC

110. Yu Y, Yang Y, Bian Y, Li Y, Liu L, Zhang H, et al. Hydrogen Gas Protects Against Intestinal Injury in Wild Type But Not NRF2 Knockout Mice With Severe Sepsis by Regulating HO-1 and HMGB1 Release. Shock (Augusta Ga.) (2017) 48(3):364-70. doi: 10.1097/SHK.0000000000000856

111. Li Y, Xie K, Chen H, Wang G, Yu Y. Hydrogen Gas Inhibits High-Mobility Group Box 1 Release in Septic Mice by Upregulation of Heme Oxygenase 1. J Surg Res (2015) 196(1):136-48. doi: 10.1016/j.jss.2015.02.042

112. Jiang Y, Bian Y, Lian N, Wang Y, Xie K, Qin C, et al. iTRAQ-Based Quantitative Proteomic Analysis of Intestines in Murine Polymicrobial Sepsis With Hydrogen Gas Treatment. Drug Des Devel Ther (2020) 14:4885-900. doi: 10.2147/DDDT.S271191

113. Vieillard-Baron A, Caille V, Charron C, Belliard G, Page B, Jardin F. Actual Incidence of Global Left Ventricular Hypokinesia in Adult Septic Shock. Crit Care Med (2008) 36(6):1701-6. doi: 10.1097/CCM.0b013e318174db05

114. Watts JA, Kline JA, Thornton LR, Grattan RM, Brar SS. Metabolic Dysfunction and Depletion of Mitochondria in Hearts of Septic Rats. J Mol Cell Cardiol (2004) 36(1):141-50. doi: 10.1016/j.yjmcc.2003.10.015

115. Brealey D, Brand M, Hargreaves I, Heales S, Land J, Smolenski R, et al. Association Between Mitochondrial Dysfunction and Severity and Outcome of Septic Shock. Lancet (London England) (2002) 360(9328):219-23. doi: 10.1016/S0140-6736(02)09459-X

116. Hanna J, Guerra-Moreno A, Ang J, Micoogullari Y. Protein Degradation and the Pathologic Basis of Disease. Am J Pathol (2019) 189(1):94-103. doi: 10.1016/j.ajpath.2018.09.004

117. Pernemalm M, Lehtiö J. Mass Spectrometry-Based Plasma Proteomics: State of the Art and Future Outlook. Expert Rev Proteomics (2014) 11(4):431-48. doi: $10.1586 / 14789450.2014 .901157$

118. Hohn A, Iovino I, Cirillo F, Drinhaus H, Kleinbrahm K, Boehm L, et al. Bioinformatical Analysis of Organ-Related (Heart, Brain, Liver, and Kidney) and Serum Proteomic Data to Identify Protein Regulation Patterns and Potential Sepsis Biomarkers. BioMed Res Int (2018) 2018:3576157. doi: 10.1155/2018/3576157

119. Dyson A, Singer M. Animal Models of Sepsis: Why Does Preclinical Efficacy Fail to Translate to the Clinical Setting? Crit Care Med (2009) 37(1 Suppl): S30-7. doi: 10.1097/CCM.0b013e3181922bd3

120. Kingsley SM, Bhat BV. Differential Paradigms in Animal Models of Sepsis. Curr Infect Dis Rep (2016) 18(9):26. doi: 10.1007/s11908-016-0535-8

121. Shah BA, Padbury JF. Neonatal Sepsis: An Old Problem With New Insights. Virulence (2014) 5(1):170-8. doi: 10.4161/viru.26906

122. Mankowski RT, Anton SD, Ghita GL, Brumback B, Cox MC, Mohr AM, et al. Older Sepsis Survivors Suffer Persistent Disability Burden and Poor Long-Term Survival. J Am Geriatrics Soc (2020) 68(9):1962-9. doi: 10.1111/ jgs. 16435

123. Ganatra HA, Stoll BJ, Zaidi AKM. International Perspective on Early-Onset Neonatal Sepsis. Clinics Perinatol (2010) 37(2):501-23. doi: 10.1016/ j.clp.2010.02.004

124. Zea-Vera A, Ochoa TJ. Challenges in the Diagnosis and Management of Neonatal Sepsis. J Trop Paediatrics (2015) 61(1):1-13. doi: 10.1093/tropej/ fmu079

125. Rowe TA, McKoy JM. Sepsis in Older Adults. Infect Dis Clinics North Am (2017) 31(4):731-42. doi: 10.1016/j.idc.2017.07.010

126. Cao Z, Yende S, Kellum JA, Angus DC, Robinson RA. Proteomics Reveals Age-Related Differences in the Host Immune Response to Sepsis. J Proteome Res (2014) 13(2):422-32. doi: 10.1021/pr400814s

127. Buhimschi CS, Bhandari V, Hamar BD, Bahtiyar M-O, Zhao G, Sfakianaki AK, et al. Proteomic Profiling of the Amniotic Fluid to Detect Inflammation, Infection, and Neonatal Sepsis. PloS Med (2007) 4(1):e18. doi: 10.1371/ journal.pmed.0040018 
128. Buhimschi CS, Bhandari V, Dulay AT, Nayeri UA, Abdel-Razeq SS, Pettker $\mathrm{CM}$, et al. Proteomics Mapping of Cord Blood Identifies Haptoglobin "Switch-on" Pattern as Biomarker of Early-Onset Neonatal Sepsis in Preterm Newborns. PloS One (2011) 6(10):e26111. doi: 10.1371/journal. pone.0026111

129. Kalenka A, Feldmann REJ, Otero K, Maurer MH, Waschke KF, Fiedler F. Changes in the Serum Proteome of Patients With Sepsis and Septic Shock. Anesthesia Analg (2006) 103(6):1522-6. doi: 10.1213/01.ane.0000 242533.59457.70

130. Raju MS VJ, Kamaraju RS, Sritharan V, Rajkumar K, Natarajan S, Kumar $\mathrm{AD}$, et al. Continuous Evaluation of Changes in the Serum Proteome From Early to Late Stages of Sepsis Caused by Klebsiella Pneumoniae. Mol Med Rep (2016) 13(6):4835-44. doi: 10.3892/mmr.2016.5112

131. Sharma NK, Tashima AK, Brunialti MKC, Ferreira ER, Torquato RJS, Mortara RA, et al. Proteomic Study Revealed Cellular Assembly and Lipid Metabolism Dysregulation in Sepsis Secondary to Community-Acquired Pneumonia. Sci Rep (2017) 7(1):15606. doi: 10.1038/s41598-017-15755-1

132. Sharma NK, Ferreira BL, Tashima AK, Brunialti MKC, Torquato RJS, Bafi A, et al. Lipid Metabolism Impairment in Patients With Sepsis Secondary to Hospital Acquired Pneumonia, a Proteomic Analysis. Clin Proteomics (2019) 16:29. doi: 10.1186/s12014-019-9252-2

133. Su L, Zhou R, Liu C, Wen B, Xiao K, Kong W, et al. Urinary Proteomics Analysis for Sepsis Biomarkers With iTRAQ Labeling and Two-Dimensional Liquid Chromatography-Tandem Mass Spectrometry. J Trauma Acute Care Surg (2013) 74(3):940-5. doi: 10.1097/TA.0b013e31828272c5

134. Su L, Cao L, Zhou R, Jiang Z, Xiao K, Kong W, et al. Identification of Novel Biomarkers for Sepsis Prognosis via Urinary Proteomic Analysis Using iTRAQ Labeling and 2D-LC-MS/MS. PloS One (2013) 8(1):e54237. doi: 10.1371/journal.pone.0054237

135. Liu J, Li J, Deng X. Proteomic Analysis of Differential Protein Expression in Platelets of Septic Patients. Mol Biol Rep (2014) 41(5):3179-85. doi: 10.1007/ s11033-014-3177-7

136. de Azambuja Rodrigues PM, Valente RH, Brunoro GVF, Nakaya HTI, AraújoPereira M, Bozza PT, et al. Proteomics Reveals Disturbances in the Immune Response and Energy Metabolism of Monocytes From Patients With Septic Shock. Sci Rep (2021) 11(1):15149. doi: 10.1038/s41598-021-94474-0

137. Shane AL, Sánchez PJ, Stoll BJ. Neonatal Sepsis. Lancet (London England) (2017) 390(10104):1770-80. doi: 10.1016/S0140-6736(17)31002-4

138. Cortese F, Scicchitano P, Gesualdo M, Filaninno A, De Giorgi E, Schettini F, et al. Early and Late Infections in Newborns: Where Do We Stand? A Review. Pediatr neonatol (2016) 57(4):265-73. doi: 10.1016/j.pedneo.2015.09.007

139. Wynn JL, Wong HR. Pathophysiology and Treatment of Septic Shock in Neonates. Clin Perinatol (2010) 37(2):439-79. doi: 10.1016/j.clp.2010.04.002

140. Buhimschi IA. Using SELDI-TOF Mass Spectrometry on Amniotic Fluid and for Clinical Proteomics and Theranostics in Disorders of Pregnancy. Methods Mol Biol (Clifton N.J.) (2012) 818:171-97. doi: 10.1007/978-161779-418-6 13

141. Sampson JE, Theve RP, Blatman RN, Shipp TD, Bianchi DW, Ward BE, et al. Fetal Origin of Amniotic Fluid Polymorphonuclear Leukocytes. Am J Obstetrics Gynecol (1997) 176(1 Pt 1):77-81. doi: 10.1016/S0002-9378(97) 80015-4

142. Gomez-Lopez N, Romero R, Xu Y, Leng Y, Garcia-Flores V, Miller D, et al. Are Amniotic Fluid Neutrophils in Women With Intraamniotic Infection and/or Inflammation of Fetal or Maternal Origin? Am J Obstetrics Gynecol (2017) 217(6):693.e1-92.e16. doi: 10.1016/j.ajog.2017.09.013

143. Kiehntopf M, Melcher F, Hänel I, Eladawy H, Tomaso H. Differentiation of Campylobacter Species by Surface-Enhanced Laser Desorption/IonizationTime-of-Flight Mass Spectrometry. Foodborne Pathog Dis (2011) 8(8):87585. doi: $10.1089 /$ fpd.2010.0775

144. Aivado M, Spentzos D, Alterovitz G, Otu HH, Grall F, Giagounidis AA, et al. Optimization and Evaluation of Surface-Enhanced Laser Desorption/ Ionization Time-of-Flight Mass Spectrometry (SELDI-TOF MS) With Reversed-Phase Protein Arrays for Protein Profiling. Clin Chem Lab Med (2005) 43(2):133-40. doi: 10.1515/cclm.2005.022

145. Marcos B, Gou P, Guàrdia MD, Hortós M, Colleo M, Mach N, et al. SurfaceEnhanced Laser Desorption/Ionisation Time-of-Flight Mass Spectrometry: A Tool to Predict Pork Quality. Meat Sci (2013) 95(3):688-93. doi: 10.1016/ j.meatsci.2012.10.014
146. Buhimschi IA, Buhimschi CS. The Role of Proteomics in the Diagnosis of Chorioamnionitis and Early-Onset Neonatal Sepsis. Clin Perinatol (2010) 37 (2):355-74. doi: 10.1016/j.clp.2010.03.002

147. Buhimschi IA, Christner R, Buhimschi CS. Proteomic Biomarker Analysis of Amniotic Fluid for Identification of Intra-Amniotic Inflammation. BJOG an Int J Obstetrics Gynaecol (2005) 112(2):173-81. doi: 10.1111/j.14710528.2004.00340.x

148. Buhimschi CS, Bhandari V, Han YW, Dulay AT, Baumbusch MA, Madri JA, et al. Using Proteomics in Perinatal and Neonatal Sepsis: Hopes and Challenges for the Future. Curr Opin Infect Dis (2009) 22(3):235-43. doi: 10.1097/QCO.0b013e32832a5963

149. Iba T, Levy JH. Inflammation and Thrombosis: Roles of Neutrophils, Platelets and Endothelial Cells and Their Interactions in Thrombus Formation During Sepsis. J Thromb Haemostasis JTH (2018) 16(2):231-41. doi: $10.1111 /$ th. 13911

150. Jacobi J. Pathophysiology of Sepsis. Am J health-syst Pharm AJHP Off J Am Soc Health-Syst Pharm (2002) 59(Suppl 1):S3-8. doi: 10.1093/ajhp/ 59.suppl_1.S3

151. Zhang H, Zhao C, Li X, Zhu Y, Gan CS, Wang Y, et al. Study of Monocyte Membrane Proteome Perturbation During Lipopolysaccharide-Induced Tolerance Using iTRAQ-Based Quantitative Proteomic Approach. Proteomics (2010) 10(15):2780-9. doi: 10.1002/pmic.201000066

152. Mann M, Jensen ON. Proteomic Analysis of Post-Translational Modifications. Nat Biotechnol (2003) 21(3):255-61. doi: 10.1038/nbt0303255

153. Li J, Paulo JA, Nusinow DP, Huttlin EL, Gygi SP. Investigation of Proteomic and Phosphoproteomic Responses to Signaling Network Perturbations Reveals Functional Pathway Organizations in Yeast. Cell Rep (2019) 29 (7):2092-104.e4. doi: 10.1016/j.celrep.2019.10.034

154. Yan-chen L, Xin L, Dan W, Cai-bin H. Advances on the Effect of PostTranslational Modification on HMGBl Localization. J Med Postgraduates (2018) 31(02):193-7. doi: 10.16571/j.cnki.1008-8199.2018.02.017

155. Hwang JS, Choi HS, Ham SA, Yoo T, Lee WJ, Paek KS, et al. DeacetylationMediated Interaction of SIRT1-HMGB1 Improves Survival in a Mouse Model of Endotoxemia. Sci Rep (2015) 5:15971. doi: 10.1038/srep15971

156. Biron BM, Chung CS, O’Brien XM, Chen Y, Reichner JS, Ayala A. ClAmidine Prevents Histone 3 Citrullination and Neutrophil Extracellular Trap Formation, and Improves Survival in a Murine Sepsis Model. J Innate Immun (2017) 9(1):22-32. doi: 10.1159/000448808

157. Li Y, Liu Z, Liu B, Zhao T, Chong W, Wang Y, et al. Citrullinated Histone H3: A Novel Target for the Treatment of Sepsis. Surgery (2014) 156(2):22934. doi: 10.1016/j.surg.2014.04.009

158. Stutz A, Kolbe CC, Stahl R, Horvath GL, Franklin BS, van Ray O, et al. NLRP3 Inflammasome Assembly is Regulated by Phosphorylation of the Pyrin Domain. J Exp Med (2017) 214(6):1725-36. doi: 10.1084/ jem.20160933

159. Tang J, Tu S, Lin G, Guo H, Yan C, Liu Q, et al. Sequential Ubiquitination of NLRP3 by RNF125 and Cbl-B Limits Inflammasome Activation and Endotoxemia. J Exp Med (2020) 217(4):e20182091. doi: 10.1084/jem.20182091

160. Kim YM, Park EJ, Kim HJ, Chang KC. Sirt1 S-Nitrosylation Induces Acetylation of HMGB1 in LPS-Activated RAW264.7 Cells and Endotoxemic Mice. Biochem Biophys Res Commun (2018) 501(1):73-9. doi: 10.1016/j.bbrc.2018.04.155

161. Nakazawa H, Chang K, Shinozaki S, Yasukawa T, Ishimaru K, Yasuhara S, et al. iNOS as a Driver of Inflammation and Apoptosis in Mouse Skeletal Muscle After Burn Injury: Possible Involvement of Sirt1 S-NitrosylationMediated Acetylation of P65 NF-kb and P53. PloS One (2017) 12(1): e0170391. doi: 10.1371/journal.pone.0170391

162. Clementi E, Brown GC, Feelisch M, Moncada S. Persistent Inhibition of Cell Respiration by Nitric Oxide: Crucial Role of S-Nitrosylation of Mitochondrial Complex I and Protective Action of Glutathione. Proc Natl Acad Sci USA (1998) 95(13):7631-6. doi: 10.1073/pnas.95.13.7631

163. Wang H, Bloom O, Zhang M, Vishnubhakat JM, Ombrellino M, Che J, et al. HMG-1 as a Late Mediator of Endotoxin Lethality in Mice. Sci (New York N.Y.) (1999) 285(5425):248-51. doi: 10.1126/science.285.5425.248

164. Deng M, Scott MJ, Fan J, Billiar TR. Location is the Key to Function: HMGB1 in Sepsis and Trauma-Induced Inflammation. J Leukoc Biol (2019) 106 (1):161-9. doi: 10.1002/JLB.3MIR1218-497R 
165. Wang H, Ward MF, Sama AE. Targeting HMGB1 in the Treatment of Sepsis. Expert Opin Ther Targets (2014) 18(3):257-68. doi: 10.1517/ 14728222.2014 .863876

166. Kang R, Chen R, Zhang Q, Hou W, Wu S, Cao L, et al. HMGB1 in Health and Disease. Mol Aspects Med (2014) 40:1-116. doi: 10.1016/j.mam.2014.05.001

167. Chen R, Kang R, Fan XG, Tang D. Release and Activity of Histone in Diseases. Cell Death Dis (2014) 5(8):e1370. doi: 10.1038/cddis.2014.337

168. Meng S, Zongmei W. Role and Mechanism of Extracellular Histones in Pulmonary Ischemia/Reperfusion Injury. Int $J$ Anesthesiol Resuscitation (2019) 03):251-5. doi: 10.3760/cma.j.issn.1673-4378.2019.03

169. Allam R, Kumar SV, Darisipudi MN, Anders HJ. Extracellular Histones in Tissue Injury and Inflammation. J Mol Med (Berl) (2014) 92(5):465-72. doi: 10.1007/s00109-014-1148-z

170. Xu J, Zhang X, Pelayo R, Monestier M, Ammollo CT, Semeraro F, et al. Extracellular Histones are Major Mediators of Death in Sepsis. Nat Med (2009) 15(11):1318-21. doi: 10.1038/nm.2053

171. Xu J, Zhang X, Monestier M, Esmon NL, Esmon CT. Extracellular Histones are Mediators of Death Through TLR2 and TLR4 in Mouse Fatal Liver Injury. J Immunol (2011) 187(5):2626-31. doi: 10.4049/jimmunol.1003930

172. Silk E, Zhao H, Weng H, Ma D. The Role of Extracellular Histone in Organ Injury. Cell Death Dis (2017) 8(5):e2812. doi: 10.1038/cddis.2017.52

173. Cheng Z, Abrams ST, Alhamdi Y, Toh J, Yu W, Wang G, et al. Circulating Histones Are Major Mediators of Multiple Organ Dysfunction Syndrome in Acute Critical Illnesses. Crit Care Med (2019) 47(8):e677-84. doi: 10.1097/ ccm.0000000000003839

174. Li Y, Liu B, Fukudome EY, Lu J, Chong W, Jin G, et al. Identification of Citrullinated Histone H3 as a Potential Serum Protein Biomarker in a Lethal Model of Lipopolysaccharide-Induced Shock. Surgery (2011) 150(3):442-51. doi: 10.1016/j.surg.2011.07.003

175. Mangan MSJ, Olhava EJ, Roush WR, Seidel HM, Glick GD, Latz E. Targeting the NLRP3 Inflammasome in Inflammatory Diseases. Nat Rev Drug Discov (2018) 17(8):588-606. doi: 10.1038/nrd.2018.97

176. Danielski LG, Giustina AD, Bonfante S, Barichello T, Petronilho F. The NLRP3 Inflammasome and Its Role in Sepsis Development. Inflammation (2020) 43(1):24-31. doi: 10.1007/s10753-019-01124-9

177. Lee S, Nakahira K, Dalli J, Siempos II, Norris PC, Colas RA, et al. NLRP3 Inflammasome Deficiency Protects Against Microbial Sepsis via Increased Lipoxin B(4) Synthesis. Am J Respir Crit Care Med (2017) 196(6):713-26. doi: 10.1164/rccm.201604-0892OC

178. Zhong M, Wu W, Wang Y, Mao H, Song J, Chen S, et al. Inhibition of Sphingosine Kinase 1 Attenuates Sepsis-Induced Microvascular Leakage via Inhibiting Macrophage NLRP3 Inflammasome Activation in Mice. Anesthesiology (2020) 132(6):1503-15. doi: 10.1097/aln.0000000000003192

179. Zhu Y, Zhengyu J, Xiaoming D. Post-Translational Modification of the NOD-Like Receptors Family Pyrin Domain Containing 3 Inflammasome and its Role in the Pathogenesis of Sepsis. Int J Anesth Resus (2021) 03):32933. doi: 10.3760/cma.j.cn321761-20200928-00249

180. Shim DW, Lee KH. Posttranslational Regulation of the NLR Family Pyrin Domain-Containing 3 Inflammasome. Front Immunol (2018) 9:1054. doi: $10.3389 /$ fimmu.2018.01054

181. Ren G, Zhang X, Xiao Y, Zhang W, Wang Y, Ma W, et al. ABRO1 Promotes NLRP3 Inflammasome Activation Through Regulation of NLRP3 Deubiquitination. EMBO J (2019) 38(6):e100376. doi: 10.15252/embj.2018100376

182. Sharawy N, Lehmann C. Molecular Mechanisms by Which iNOS Uncoupling can Induce Cardiovascular Dysfunction During Sepsis: Role of Posttranslational Modifications (PTMs). Life Sci (2020) 255:117821. doi: $10.1016 /$ j.lfs.2020.117821
183. Stomberski CT, Hess DT, Stamler JS. Protein S-Nitrosylation: Determinants of Specificity and Enzymatic Regulation of S-Nitrosothiol-Based Signaling. Antioxid Redox Signal (2019) 30(10):1331-51. doi: 10.1089/ars.2017.7403

184. Palmieri EM, McGinity C, Wink DA, McVicar DW. Nitric Oxide in Macrophage Immunometabolism: Hiding in Plain Sight. Metabolites (2020) 10(11):429. doi: 10.3390/metabo10110429

185. Bailey JD, Diotallevi M, Nicol T, McNeill E, Shaw A, Chuaiphichai S, et al. Nitric Oxide Modulates Metabolic Remodeling in Inflammatory Macrophages Through TCA Cycle Regulation and Itaconate Accumulation. Cell Rep (2019) 28(1):218-30.e7. doi: 10.1016/ j.celrep.2019.06.018

186. Doulias PT, Tenopoulou M, Greene JL, Raju K, Ischiropoulos H. Nitric Oxide Regulates Mitochondrial Fatty Acid Metabolism Through Reversible Protein S-Nitrosylation. Sci Signal (2013) 6(256):rs1. doi: 10.1126/ scisignal.2003252

187. Everts B, Amiel E, van der Windt GJ, Freitas TC, Chott R, Yarasheski KE, et al. Commitment to Glycolysis Sustains Survival of NO-Producing Inflammatory Dendritic Cells. Blood (2012) 120(7):1422-31. doi: 10.1182/ blood-2012-03-419747

188. de Jesus JR, da Silva Fernandes R, de Souza Pessôa G, Raimundo IM and Arruda MAZ. Depleting High-Abundant and Enriching Low-Abundant Proteins in Human Serum: An Evaluation of Sample Preparation Methods Using Magnetic Nanoparticle, Chemical Depletion and Immunoaffinity Techniques. Talanta (2017) 170:199-209. doi: 10.1016/j.talanta.2017.03.091

189. Palstrøm NB, Rasmussen LM, Beck HC. Affinity Capture Enrichment Versus Affinity Depletion: A Comparison of Strategies for Increasing Coverage of Low-Abundant Human Plasma Proteins. Int J Mol Sci (2020) 21(16):5903. doi: $10.3390 /$ ijms 21165903

190. Ke M, Shen H, Wang L, Luo S, Lin L, Yang J, et al. Identification, Quantification, and Site Localization of Protein Posttranslational Modifications via Mass Spectrometry-Based Proteomics. Adv Exp Med Biol (2016) 919:345-82. doi: 10.1007/978-3-319-41448-5_17

191. Cerný M, Skalák J, Cerna H, Brzobohatý B. Advances in Purification and Separation of Posttranslationally Modified Proteins. J Proteomics (2013) 92:2-27. doi: 10.1016/j.jprot.2013.05.040

192. Wozniak JM, Mills RH, Olson J, Caldera JR, Sepich-Poore GD, CarrilloTerrazas M, et al. Mortality Risk Profiling of Staphylococcus Aureus Bacteremia by Multi-Omic Serum Analysis Reveals Early Predictive and Pathogenic Signatures. Cell (2020) 182(5):1311-27.e14. doi: 10.1016/ j.cell.2020.07.040

Conflict of Interest: The authors declare that the research was conducted in the absence of any commercial or financial relationships that could be construed as a potential conflict of interest.

Publisher's Note: All claims expressed in this article are solely those of the authors and do not necessarily represent those of their affiliated organizations, or those of the publisher, the editors and the reviewers. Any product that may be evaluated in this article, or claim that may be made by its manufacturer, is not guaranteed or endorsed by the publisher.

Copyright $(\odot 2021$ Miao, Chen and Ding. This is an open-access article distributed under the terms of the Creative Commons Attribution License (CC BY). The use, distribution or reproduction in other forums is permitted, provided the original author(s) and the copyright owner(s) are credited and that the original publication in this journal is cited, in accordance with accepted academic practice. No use, distribution or reproduction is permitted which does not comply with these terms. 